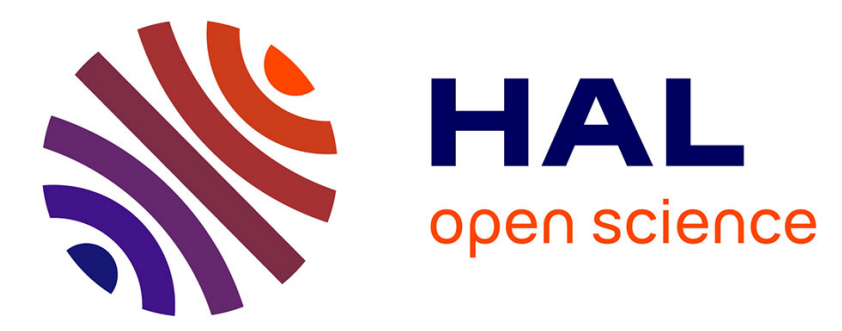

\title{
On-site characterization of the spatio-temporal structure of the noise for MRS measurements using a pair of eight-shape loops
}

\author{
Jean-Francois Girard, Clara Jodry, Pierre-Daniel Matthey
}

\section{To cite this version:}

Jean-Francois Girard, Clara Jodry, Pierre-Daniel Matthey. On-site characterization of the spatiotemporal structure of the noise for MRS measurements using a pair of eight-shape loops. Journal of Applied Geophysics, 2020, pp.104075. 10.1016/j.jappgeo.2020.104075 hal-02632514

\section{HAL Id: hal-02632514 https://hal.science/hal-02632514}

Submitted on 27 May 2020

HAL is a multi-disciplinary open access archive for the deposit and dissemination of scientific research documents, whether they are published or not. The documents may come from teaching and research institutions in France or abroad, or from public or private research centers.
L'archive ouverte pluridisciplinaire HAL, est destinée au dépôt et à la diffusion de documents scientifiques de niveau recherche, publiés ou non, émanant des établissements d'enseignement et de recherche français ou étrangers, des laboratoires publics ou privés. 


\section{Journal Pre-proof}

On-site characterization of the spatio-temporal structure of the noise for MRS measurements using a pair of eight-shape loops

Jean-François Girard, Clara Jodry, Pierre-Daniel Matthey

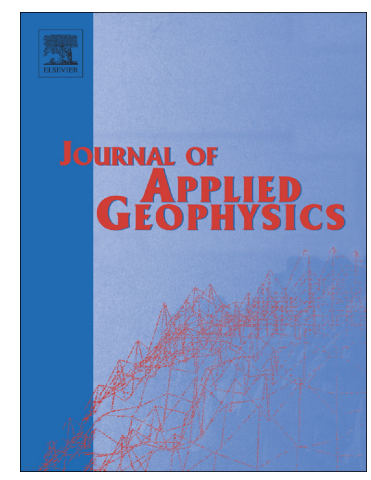

PII:

S0926-9851(19)30676-7

DOI: https://doi.org/10.1016/j.jappgeo.2020.104075

Reference:

APPGEO 104075

To appear in:

Journal of Applied Geophysics

Received date:

30 July 2019

Revised date:

9 May 2020

Accepted date:

17 May 2020

Please cite this article as: J.-F. Girard, C. Jodry and P.-D. Matthey, On-site characterization of the spatio-temporal structure of the noise for MRS measurements using a pair of eight-shape loops, Journal of Applied Geophysics (2019), https://doi.org/10.1016/ j.jappgeo.2020.104075

This is a PDF file of an article that has undergone enhancements after acceptance, such as the addition of a cover page and metadata, and formatting for readability, but it is not yet the definitive version of record. This version will undergo additional copyediting, typesetting and review before it is published in its final form, but we are providing this version to give early visibility of the article. Please note that, during the production process, errors may be discovered which could affect the content, and all legal disclaimers that apply to the journal pertain.

(C) 2019 Published by Elsevier. 


\title{
On-site characterization of the spatio-temporal structure of the noise for MRS measurements using a pair of eight-shape loops
}

\author{
By \\ Jean-François Girard $^{1}$, Clara Jodry ${ }^{1}$ and Pierre-Daniel Matthey ${ }^{1}$ \\ 1. Institut de Physique du Globe de Strasbourg, Université de Strasbourg/EOST, CNRS
}

Corresponding author : jf.girard@unistra.fr 5 rue Descartes, F - 67084 Strasbourg Cedex

\begin{abstract}
Many methodologies have been proposed to improve the signal to noise ratio of the magnetic resonance measurements. Nevertheless, in many places MRS remains unrealizable even though it would provide valuable contribution. We propose to combine figure-of-eight shape loops with multichannel equipment to challenge this issue.

We propose to use the gradient of the vertical component of the magnetic field measured via a pair of small figure-of-eight loops to estimate the noise in a large eight-s. ' pe loop of any orientation. We demonstrate on synthetic data the efficiency and limitation of this annrom $h$. The methodology applied on a field dataset allows finding a stable best direction in this case ano underlines a surprising roughly common behavior for the harmonics of the industrial current an'. ceyuencies in-between where a less organized structure was expected.

This approach proves to be a convenient and efficient $W_{4}$ y to characterize quickly a site before measuring a MRS sounding, to choose the optimal ori nla ion of the MRS loop, and provide an estimate of the final noise level that can be expected.
\end{abstract}

Key words: MRS, EM noise, eight-shape loops.

\section{Introduction}

In the last decades, magnetic resonance soundir: (MuS) has been recognized as a reliable tool for groundwater resources exploration and man zer ent in the first hundred meters of the subsurface. It is the only geophysical method solely sensitive $t, d$ the presence of the underground water through the interaction of an induced magnetic field and the s.agnetic moments of protons in the water molecules. As such, it allows direct determination of ise water content and permeability of the aquifers relative to depth (Legchenko and Valla, 200\%). : TRS is nowadays applied in various geological contexts, mainly due to ongoing development $\mathrm{s}$ is ained over the years to wider its field of application (Behroozmand, et al., 2015).

Susceptibility to noise and a por sicnal-to-noise $(\mathrm{S} / \mathrm{N})$ ratio is still the main limitation of MRS measurements. Researchers' pi nal; goal has always been to diminish its sensitivity to environmental and anthropogenic electromas etic noise since it is often of much greater amplitude than the signal induced by the presence of wa ${ }^{+}$I (e.g. Legchenko, 2007; Walsh, 2008; Larsen, Dalgaard and Auken, 2014; Müller-Petke an` ( sta sel, 2014). Over the years, two strategies have been instigated to improve the signal-to-nois ratio: (i) the increase of the signal amplitude and (Grombacher and Knight, 2015; Grunewali, et al., 2016; Lin et al., 2018); (ii) the suppression of the EM noise (Trushkin et al., 1994; Legchenko and Valla, 2003; Dalgaard et al., 2012; Costabel and Müller-Petke, 2014; Larsen et al. 2013; Larsen and Behroozmand, 2016, Kremer et al., 2019).

In this paper, we concentrate on the mitigation of the noise and see that either hardware and/or software methodologies have been implemented, (Larsen and Behroozmand, 2016; Ibrahim et al., 2018). The main hardware developments are the use of a figure-8 loop to measure the MRS signals established early on by Trushkin et al. (1994) and the multichannel instruments (Walsh, 2008). These improvements are combined to various processing procedures (Legchenko and Valla, 2003; Dalgaard et al., 2012; Costabel and Müller-Petke, 2014; Larsen et al. 2013; Larsen and Behroozmand, 2016). Nevertheless, these technics highly depend on the temporal and spatial variation of the surrounding noise, as well as the number of the sources and, even when the noise mitigation is considered effective, the signal-to-noise ratio in MRS measurements remains low (Grunewald et al., 2016).

One way to better take into consideration the complexity of the noise is through noise mapping. Locating the noise sources allows the optimization of the MRS layout, and so, achieve higher S/N ratios. To this goal, Dalgaard et al. (2014) presented a multichannel noise collector instrument (nC) to 
analyze, prior to MRS measurements, the spatial and temporal variations of the noise and obtain a comprehensive noise map. However, these measurements are not synchronous with the MRS campaign and as said before the noise can vary considerably over time especially if we consider that a single sounding can lasts several hours and cover day and night times. This is especially true for the noise originating from the harmonics due to the electric powerlines, which is dependent to human activities. In this case, the main sources can vary with time and the optimized MRS placement will vary with it. When using the figure-8 loops soundings (Trushkin et al., 1994), loop axis has to be parallel to the main powerline to maximize the noise reduction. It is noteworthy that in peri-urban environment, when the noise is expected to be high, the figure-8 loop is often the only available possibility to avoid saturating the instrument. Yet, the estimation of the best direction in the vicinity of a network of powerlines is not easy.

In this paper, we seek to respond to this issue with the use of figure-8 loops and the multichannel MRS instrumentation. We introduce two remote smaller figure-8 loop placed perpendicularly to each other to record the noise. We show that it allows an estimation in advance of the optimum placement for the MRS sounding. A first part covers the basics of MRS measuremer and the state-of-the art of noise removal strategies. A second part develops the equations of powerline acording using a pair of figure8 loops. Part 3 presents some synthetic case studies. Then a fourt' 1 pa $t$ confronts the approach to the field conditions in a dedicated case study.

\section{Basics of MRS and noise removal}

Magnetic resonance phenomenon is based on the perturb: ion of the nuclear magnetic spins, i.e. magnetic moments, of hydrogen nuclei (protons) in grr un ' $w a t e r$. At any given time, the proton magnetic moments are naturally aligned to the local earth : $m$.gnetic field $B_{0}$ and precess around it at an angular frequency called Larmor frequency, $f_{0}=\omega_{\mathrm{v}} / 2 \pi=\gamma B_{0} / 2 \pi$, dependent on the amplitude of the geomagnetic field $B_{0}$ and the gyromagnetic 1 at ${ }^{\prime} ;$ '. On Earth, given the geographic location of the study area, the Larmor frequency varies betw $\mathrm{se}_{\mathrm{t}}{ }^{\mathrm{o}} \mathrm{r}_{\mathcal{N}}$ and $2,800 \mathrm{~Hz}$ (Legchenko and Valla, 2002). This alignment generates an equilibrium $\mathrm{m}^{\text {gn }} \mathrm{tiz}_{\mathrm{u}}$ ion of the groundwater $M_{0}$, the magnitude of which is proportional to the number of pro $n^{\prime} \mathrm{s}$ in liquid water but usually too small to be measured directly (Müller-Petke et al., 2013).

To measure the MRS signal, a magnetic field $B_{1}(t)$ is produced by way of energizing a surface transmitter loop with a pulse of alterr $\iota_{\text {s }}$-current $i(t)=I_{0} \cos (\omega t)$ at the frequency $\omega \approx \omega_{0}$ to create resonance condition. This second $\mathrm{m}$ ıgnetic field tilts $M_{0}$ depending on the pulse moment $q=$ $I_{0} \tau$, with $I_{0}$ and $\tau$ being the ampliture a. $d$ duration of the pulse respectively. After shutting down the pulse current, the magnetic moments : aturn back gradually to align with earth's magnetic field again. This relaxation process induces a nagnetic field large enough to generate a perceptible alternative voltage $E(t)$ in a surface rec iver vop:

$$
E(t)=E_{0} e^{-\frac{1}{T_{2}^{*} t} \operatorname{cor}\left(21, f_{0} t \cdot-\text { phase }_{m r s}\right)}
$$

The relaxation signal $E(t)$, ecreases exponentially with time $t$ (called Free Induction Decay, or FID signal) and oscillate at the Larmor frequency. It is characterized by an initial amplitude $E_{0}$ related to the amount of free water in the soil and the decay time constant $T_{2}^{*}$ that describes how quickly the magnetization returns to the original alignment and is linked to the distribution of pore sizes in the soil containing the water. A phase shift phase $e_{m r s}$ generally occurs if the ground is conductive (Legchenko et al., 2008) or if the exciting frequency is not exactly at the Larmor frequency. Quantitative information on the spatial distribution of the water content is then obtained by a kernel-based inversion process of $E_{0}$ and $T_{2}^{*}$ data for a given acquisition parameters set: size and shape of the loop, pulse intensity, geomagnetic field, etc..., (Legchenko, 2013).

In practice, a single sounding is composed of series of energizing pulses of increasing amplitude values that excite deeper hydrogen nuclei. The depth of investigation depends on the electrical conductivity of the subsurface and the loop size. The loop (or loops) is usually a square or figure- 8 square loop with sides between 20 and $150 \mathrm{~m}$ which commonly allows a depth of investigation between 30 to $100 \mathrm{~m}$ (Behroozmand et al., 2015). We note that, in general, the same loop is used for transmission and reception. However, the two loops can be separated while remaining close enough to one another to maintain sensitivity (Hertrich et al., 2005) which allows detailed 2D and 3D images (e.g. Jiang et al., 2015). 
The MRS response from groundwater is usually of a few $n V$ to a hundreds $n V$, which makes it far smaller than the ambient electromagnetic noise resulting in potential misinterpretation of hydrogeological parameters. It is therefore of paramount importance to develop measurements and digital filtering protocols to reduce the influence of this noise in the recorded signal.

MRS measurements are contaminated by three different noise sources in constant evolution over time $t$ (Dalgaard et al., 2014). First, the electrical discharges, known as spikes $s p(t)$, induce short impulses that originate from both natural and artificial sources (e.g. lightning/thunderstorms, electrical fences, generators). Second, the harmonic noise commonly attributed to powerlines harmonics $h(t)$ and finally the random and generally Gaussian distributed white noise $r(t)$, i.e. the ambient noise:

$$
E(t)=F I D(t)+s p(t)+h(t)+r(t)
$$

Records affected by spikes-like noises can be rejected either during the measurement using an amplitude threshold, but it results in longer acquisition duration, or could be treated later through signal processing. Many despiking strategies include detection and rejection through a chosen threshold. Either in the time domain (Legchenko, 2007; Dalgaard $\because: a l ., 2012$ ) or wavelet-domain (Costabel and Müller-Petke, 2014). Other procedures explore reiectı? through statistical stacking (Jiang et al., 2011) and subtraction-based approach (Larsen, :016, with various success. Since impulsive noises are of high-amplitude and wide bandwidth, $t^{1}$. : $:$ moval prior to harmonic noise cancellation is essential (Dalgaard et al., 2012; Costabel and N iiller Petke, 2014; Hein et al., 2017). It has also to be taken into account that the shape of the spik, will vary according to its origin and the filters of the recording device (Larsen, 2016).

The powerlines harmonics are almost sinusoids whose fr quencies are integer multiples of the fundamental frequency, generally 50 or $60 \mathrm{~Hz}$ dependin s on 'he country power grid (Legchenko and Valla, 2003). Their amplitude is often much stronge th d' natural noise, which can be a problem when the Larmor frequency is close to one of these an...ics (Dalgaard et al., 2014). Many software procedures have been implemented to rems $n$ or diminish their effect either in time or frequency domain. The Notch filter has proven to $i$ e ficient when the frequency difference between the harmonic and the Larmor frequency is at least $\& 4 \mathrm{~Hz}$ at the risk, otherwise, to distort the MRS signal (Legchenko and Valla, 2003). It is imp rant to note that it is generally based on predetermined frequency component without regards $i^{-r}$ he instability over time of the fundamental frequency. However, it is well known that the powf rli ie induced signals constantly fluctuate in amplitude, phase and frequency according to changes in s. nply and demands (Legchenko and Valla, 2003; Larsen et al., 2013; Girard et al., 2015, Kremer et . . ., 2019). This issue is addressed partially in the adaptive notch filter (Jiang et al., 2011) and the mu del-based approach (Larsen et al., 2013) even though they assume constant noise structure over the a ration of one record (less than a few seconds). These methods can

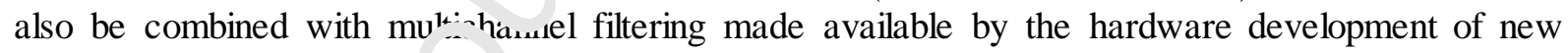
multichannel MRS eqrinm. 'nt ( Radic, 2006; Walsh, 2008; Dlugosch et al., 2011). This development marks a new era regardin $r_{c}$ noise reduction using remote reference loops in the area of investigation to filter the noise recorded ir the recording loop. Since, different processing algorithms have been developed using multichannel MRS signals (Dalgaard et al., 2012; Müller-Petke and Costabel, 2014). The efficiency of the multichannel filtering techniques is generally limited in multisource environment (Larsen et al., 2013; Larsen, 2016) and by the timing jitter between channels in the recording instruments (Dalgaard et al., 2012; Larsen and Behroozmand, 2016), although the last is said to have limited effect (Walsh, 2008).

The ambient noise is characterized as uncorrelated, broadband and Gaussian distributed white noise and may represent the majority of the noise energy (Legchenko, 2007). It is commonly reduced by repeated measurements and stacking methods (Legchenko and Valla, 2002; Dalgaard and Auken, 2016; Larsen and Behroozmand, 2016; Hein et al., 2017). In practice, it is a slow, even though efficient, process where the noise is suppressed by averaging all the signal records for a given pulse moment with a decrease in $1 / \sqrt{N}$ where $\mathrm{N}$ is the number of records in a stack (Legchenko, 2007; Grunewald et al., 2016). Stacking has also proven to reduce harmonic noise based on the fact that the phases of said noise change randomly with every single record (Legchenko and Valla, 2003; Strehl, 2006; Ghanati et al., 2016). 
The remaining noise (e.g. broadband ambient noise, harmonic components unrelated to powerline and instruments noise) can also be mitigated with a low-pass filter and/or pass-band filter (centered at the Larmor frequency) (Legchenko and Valla, 2002).

Finally, other software approaches to reduce signal-to-noise include new complex filtering strategies based on statistical processes and spectrum analyses (Chen et al., 2016; Ghanati et al., 2016; Hein et al., 2017; Ibrahim et al., 2018).

When considering the hardware based noise mitigation method, early on, Trushkin et al. (1994) introduced the use of a figure- 8 loop instead of the usually square or circle loop, when the noise level is particularly high and cause instrumental saturation. In this configuration, the noise is recorded in both parts of the eight-shaped loop with opposite polarity. If the noise field is homogeneous across the loop surface, the noise from the first loop is compensated by the noise in the second loop. At the contrary, since the current circulates in opposite direction in both loop, the MRS signal is added. The orientation of the loop axis is optimized to minimize the noise induced voltage and often ends up parallel to the closest powerline (Liebich et al., 1994; Trushkin et al., 1994; Plata and Rubio, 2002; Chalikakis et al., 2008). The main drawback is loss of depth of in estigation compared to square or circular loops (Legchenko, 2005) and its efficiency depends $n$ the homogeneity of the electromagnetic noise as well as the number of noise sources (Wr sh, ?.008). Other researchers have pointed out that the interpretation of the MRS data recorded with a "m e-8 loop can be problematic as the magnetic field excitation is not fully understood and that the sensitivity function is more complicated (Dlugosch et al., 2011; Dalgaard et al., 2014). Neveı i.eless, its ease of implantation make it one of the most used design.

More recently, other hardware have been introduced $\mathrm{v}$ th $\mathrm{f}$ omising efficiency (Díaz-Curiel et al., 2011; Davis et al., 2014; Behroozmand et al., 2016) and riea 'rements of the three components of the magnetic field instead of only the vertical comp «n have been explored (Radic, 2006, 2009; Costabel and Müller-Petke, 2014; Müller-Petke anc 'o tabel, 2014; Girard et al., 2015; Kass et al., 2017; Costabel, 2019).

Hence, much research led to hardware an' sof ware development and the processing sequences are often combined in a workflow to successfully to enhance the signal-to-noise ratio (Behroozmand et al., 2015; Dalgaard and Auken, 2016; Thanati et al., 2016; Müller-Petke et al., 2016; Hein et al., 2017, Liu et al. 2018, 2019).

\section{Powerline recording using î al $\llcorner-8$ loops}

In order to improve harmonic nois n itlyation, it is necessary to better apprehend magnetic fields produced by powerlines and in $\mathrm{m}$. analyze the magnetic flux and the electromotive force (emf) induced through a conductive loop ' $x$ cated in the vicinity.

For sake of simplicity, we consia $r$ powerlines as infinite long straight wireline that are traversed by an alternating current $\mathrm{I}(t)-\Sigma_{n=0}^{N} \mathrm{I}_{\mathrm{k}} \sin \left(\omega_{k} t+\varphi_{k}\right)$ composed of harmonics of a fundamental frequency $(50 \mathrm{~Hz}$ in Franct $)$ wit $\mathrm{I}$ an angular frequency $\omega_{k}=2 \pi f_{k}$. The fundamental frequency shows variations on the range vi a $1 \mathrm{eW}$ tens of $\mathrm{mHz}$ (Liu et al., 2018; Costabel, 2019, Kremer et al., 2019) which corresponds to a vari tion of a few $\mathrm{Hz}$ when regarding the higher harmonics in the MRS range. Note that generally all powerlines on the same grid have the same instantaneous frequency but various phases and amplitudes, and thus can hardly be distinguished from one another. We place ourselves in a context where powerlines are close enough to MRS loop to be considered as infinite and then the strength of the vertical component of the generated magnetic field decreases as $1 / \mathrm{r}$ where $\mathrm{r}$ is the distance from the powerline (Sternberg, 2010; Yang et al., 2013; Dalgaard et al., 2014). Using the Biot-Savart formula, the vertical component of a magnetic field $B_{z}$ generated by an infinite wire conductor laid on an infinitely resistive ground is as follow:

$$
B_{z}= \pm \frac{\mu_{0} I(t)}{2 \pi r}
$$

with $r(\mathrm{~m})$ being the distance of the measurement point perpendicularly to the powerline and $\mu_{0}$ the magnetic permeability $\left(4 \pi \cdot 10^{-7} \mathrm{~T} . \mathrm{m} / \mathrm{A}\right)$. The polarization $( \pm)$ of the magnetic field refers to the sign of the current I (A) and the position of the measure point according to the powerline.

Following Faraday's law, the flux of $B \Phi_{B}$ through a loop of surface $\mathrm{S}$ induces an emf $\varepsilon$ (in V) equal to: 


$$
\varepsilon=-\frac{d \Phi_{B}}{d t}
$$

Considering $\mathrm{S}$, the surface of the recording loop, then the flux is:

$$
\Phi_{B}=\iint_{S} \overrightarrow{B_{Z}} \cdot \overrightarrow{d S}
$$

Combining equation (3), (4) and (5), we obtain the theoretical emf in a closed circuit due to a powerline:

$$
\varepsilon=( \pm) \frac{\mu_{0}}{2 \pi} \frac{d}{d t} I(t) \oiint_{S} \frac{1}{r} d S
$$

Therefore, knowing the term $\oiint_{S} \frac{1}{r} d S$, we can calculate the emf in a MRS loop, depending on its distance to the powerline.

If we assumed that the vertical component of the magnetic field $B$ is oustant over the surface of the loop (or linearly varying, see annex for details), it allows us to at nroy mate at the second order the flux as:

$$
\oiint_{S} \frac{1}{r} d S \approx \frac{S}{r}
$$

where $r$ is the distance to the center of the loop. Then th em is expressed as:

$$
\varepsilon \approx( \pm) \frac{\mu_{0}}{2 \pi} \frac{S}{r} \frac{d}{d t} I(t)
$$

Figure 1a compares the emf over distance ( 1 , from the center of the loop to the powerline obtained with equation (6) and (8), referred in Fig -re la as "exact" and "approximated" emf (respectively) for square loops of different sizes (where I : $\mathrm{t}_{\mathrm{h}}$. loop side of $20 \mathrm{~m}, 40 \mathrm{~m}$ and $75 \mathrm{~m}$ ). The square has one side parallel to a powerline with a curr $\mathbf{n}, \mathrm{t} u$ wing through of $\mathrm{I}_{0}=1 \mathrm{~mA}$ (I>0 along $\vec{u}$ ) at $2050 \mathrm{~Hz}$ (see annex 1 for comments on the int $11 \mathrm{~s}^{\circ} \mathrm{v}$ value), i.e. $I(t)=I_{0} \sin \left(\omega_{0} t+\right.$ phase $\left._{0}\right)$. The difference of amplitude between the two is red $k$ d as the distance increases and the size of the loop diminishes. Figure $1 \mathrm{~b}$ represents the calcula ${ }^{+}$ed relative error between the two calculations for a distance normalized by the loop size $(\mathrm{r} / \mathrm{L})$. The three curves coincide, and we can see that, when the distance between the closest side of the 1r sp and the powerline is equal to one time the size of the loop $(\mathrm{r} / \mathrm{L}$ $>1.5$ ), the ratio is always b low $5 \%$. It reduces below $1 \%$ for a distance equal to three times the size of the loop.
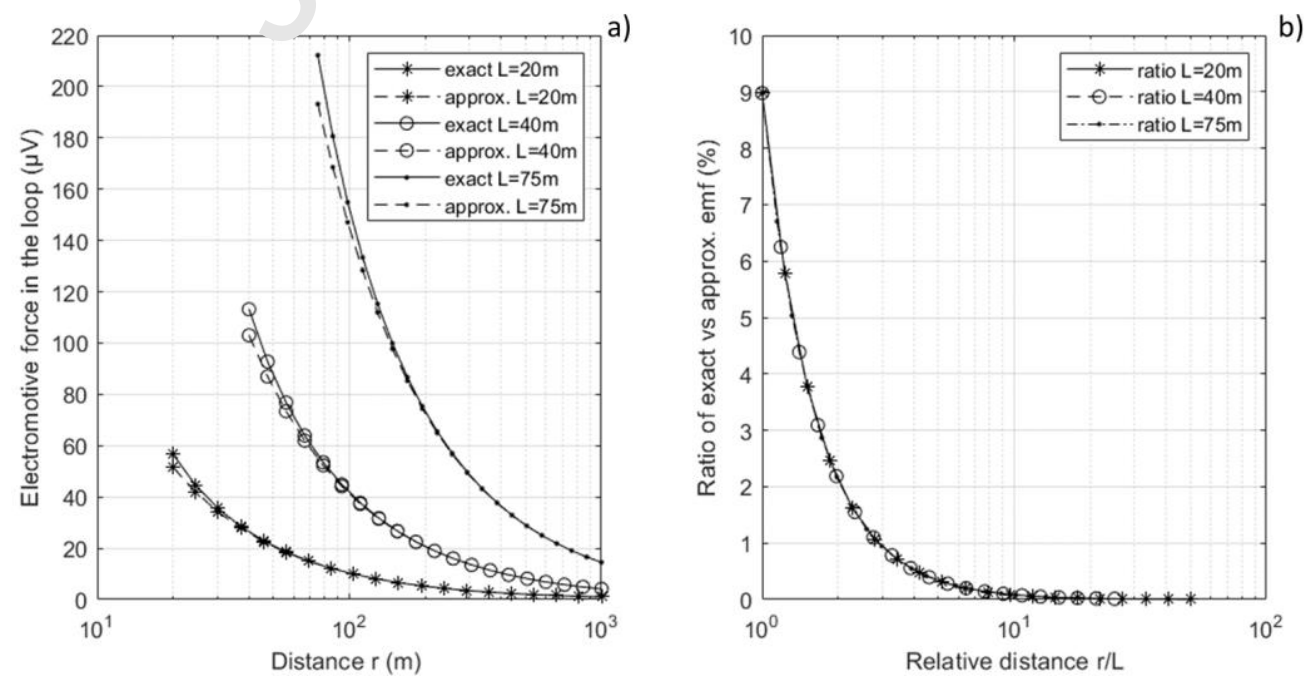
Figure 1. a) electromotive force (emf) at the terminals of the square loop using an exact integration (-) versus the approximation using the value at the center of the loop (-.-) and b) the relative error between the two responses as a percentage error for square loop of sizes $20 \mathrm{~m}(),. 40 \mathrm{~m}(*)$ and $75 \mathrm{~m}(\mathrm{o})$.

When considering a figure- 8 loop (see Figure 2), the emf $\varepsilon$ is the sum of the two emf $\varepsilon_{1}$ and $\varepsilon_{2}$ of the two square loops centered in $C_{1}$ and $C_{2}$ with surfaces $S_{1}$ and $S_{2}$, which compose the figure-8 loop:

$$
\begin{aligned}
\varepsilon & =\varepsilon_{1}+\varepsilon_{2}=-\frac{d}{d t}\left[\oiint_{S_{1}} \vec{B} \cdot \overrightarrow{d S}+\oiint_{S_{2}} \vec{B} \cdot \overrightarrow{d S}\right] \\
\varepsilon & \approx-\frac{d}{d t}\left[\operatorname{pol}_{1} S_{1} B_{Z}^{1}+\operatorname{pol}_{2} S_{2} B_{Z}^{2}\right]=-\frac{d}{d t}\left[B_{Z}^{1}-B_{Z}^{2}\right] S \text { pol }
\end{aligned}
$$

with the polarity convention $\operatorname{pol}_{1}=-\operatorname{pol}_{2}=+p o l,(p o l= \pm 1)$ and the two square loops of the same size: $S_{1}=S_{2}=S$ the emf is proportional to the time derivative of the gradient of the vertical component of the magnetic field $\frac{\partial}{d t} \nabla B_{Z}$ along the figure- 8 loop axis, at the center of the loop: $B_{Z}^{1}-$ $B_{z}^{2} \approx \overrightarrow{\nabla B_{z}} \cdot \overrightarrow{C_{2} C_{1}}$.

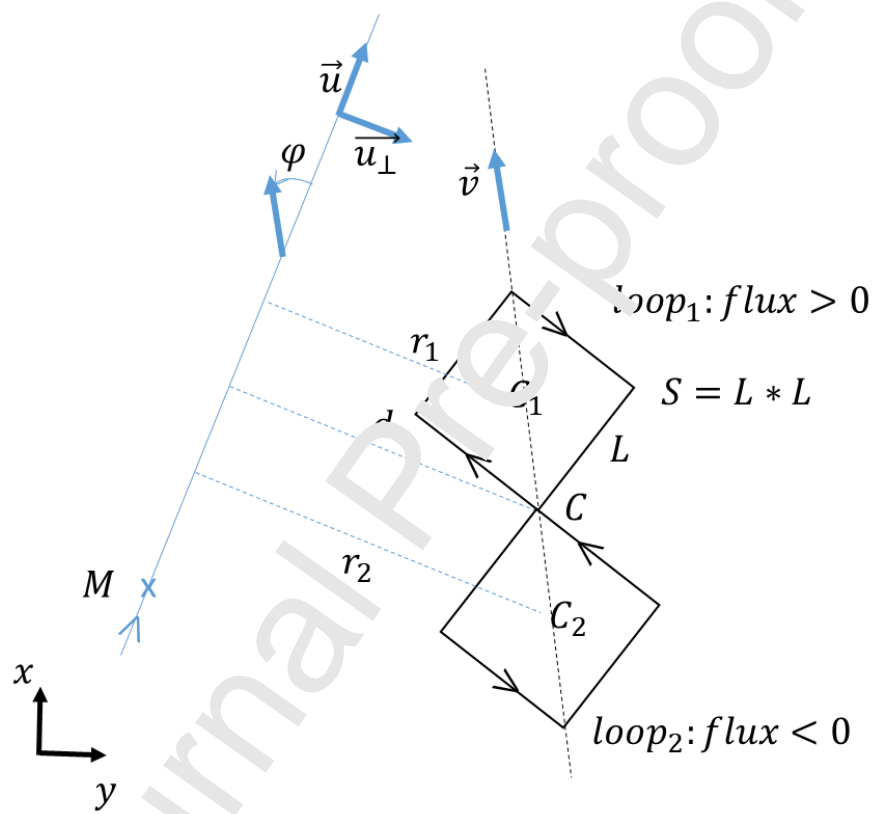

Figure 2. geometry of a figur 8 k op consisting of two square loops of side length $L$ (and surface $S$ ) centered in $C_{1}$ and $C_{2}$ at d sta. e $r_{1}$ and $r_{2}$ respectively from a nearby straight powerline defined by a point $M$ and a vector $\vec{u}\left(\vec{u}_{\perp} \vec{r}\right.$ ing perpendicular to the powerline). The axis of the figure-8 loop is defined by vector $\vec{v}$ and the angle with the powerline direction $\vec{u}$ is called $\varphi$. Point $C$ is the center of the figure- 8 (and common point between the two square loops) at distance $d$ from the powerline. The convention of sign is such that here the flux of the powerline field $\vec{B}$ is accounted positively in the square loop $\mathrm{n}^{\circ} 1$ (the northern) and negatively in the square loop $\mathrm{n}^{\circ} 2$

Considering the scheme in Figure 2, one can write the emf in terms of the gradient of the vertical component of the magnetic field:

$\varepsilon_{\text {grad }} \approx-\vec{\nabla}\left(\frac{\partial B_{Z}}{\partial t}\right) \cdot \overrightarrow{C_{2} C_{1}} S$ pol

Considering approximation in equation (7) and (8), and if the powerline does not cross the figure- 8 loop (i.e., $C, C_{1}, C_{2}$ are on the same side of the powerline), the figure- 8 loop response estimated from the difference of emf is (see annex 2 for some details on the approximation):

$\varepsilon_{\text {diff }}=-\frac{\mu_{0}}{2 \pi} \frac{d I}{d t} \operatorname{sign}\left(\overrightarrow{M C} \cdot \overrightarrow{u_{\perp}}\right)$ pol $S\left[\frac{1}{r_{1}}-\frac{1}{r_{2}}\right]$ 
Figure 3 compares the emf over distance obtained with equation (11) and (12) for a figure-8 loop consisting of two square of $40 \mathrm{~m}$ sides located at 80,100 and $120 \mathrm{~m}$ from a powerline in which flows a current of $1 \mathrm{~mA}$ at $2050 \mathrm{~Hz}$. As expected, when the axis of the figure- 8 loop is parallel to the powerline, the response vanishes. At distance $\mathrm{d}=80 \mathrm{~m}$, in the worst case (i.e. angle of the axis equal to $90^{\circ}$ ) the closest square loop is located $56 \mathrm{~m}$ from the powerline and $112 \mathrm{~m}$ for the farthest. From curves in Figure 1a, their emf are 80 and $38 \mu \mathrm{V}$ respectively, explaining the $42 \mu \mathrm{V}$ value in Figure $3 \mathrm{a}$. Therefore, even if the figure- 8 loop has a bad orientation, the noise is lower than in a square loop of same size and the noise level in the figure- 8 is close to the quieter square loop.

The amplitude of emf decreases with distance to the powerline. Farther, the orientation of the figure- 8 loop has a less drastic influence even if it remains sensitive. Figure 3a reports a small amplitude difference between the two approximations to calculate the emf. The difference rises for angle close to $90^{\circ}$ and when closer to the powerline (see Figure 3b, maximum difference is $13 \%$ at $80 \mathrm{~m}$ and $5.5 \%$ at $120 \mathrm{~m}$ ). Not surprisingly, the analogy between the figure- 8 emf and the "gradient of the noise" is weaker when the gradient is strong. Practically, we expect that the use of a pair of small figure-8 loops, as described below, to estimate the noise in the targeted lar se MRS figure- 8 loop will be less efficient in these cases.

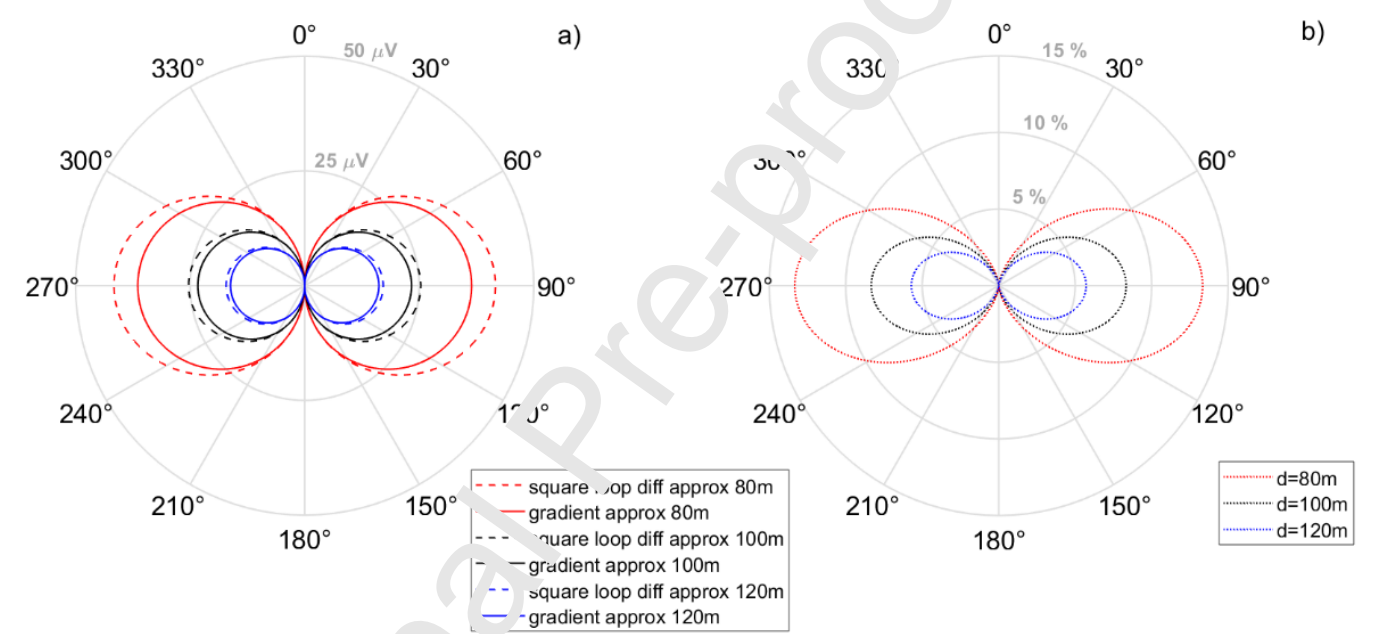

Figure 3. a) emf voltage of the fig re- 8 ioop using the square loops emf difference approximation (-) versus the gradient approximatio: (--) for three fixed distances $80 \mathrm{~m}, 100 \mathrm{~m}$ and $120 \mathrm{~m}$ and varying angle between the figure- $8 \operatorname{loc}_{1}$ a ais and the powerline and b) relative error between the two approximations.

Our first example conside s o. ${ }^{y} y$ one powerline and one can use a figure- 8 square loop with the axis parallel to this powerlinc ${ }^{+} \mathrm{O}$ in in the best noise reduction. However, the noise structure can be more complicated when consider $\mathrm{g}$ multiple sources of noise (powerlines, pumpings, electric engines, etc.) reducing the chances to rild an optimal direction. We propose to use the gradient of the vertical component of the magnetic field as a rather good estimator of the noise in a figure-8 loop. Following equation (11) and the geometry depicted in Figure 2, for a figure-8 loop with square sides L, and Ntr turns of wires, , noticing $\overrightarrow{C_{2} C_{1}}=\sqrt{2} L \vec{v}$ with $\vec{v}$ being the unitary vector along the figure-8 loop axis, then:

$$
\varepsilon \approx-L^{3} \sqrt{2} N \operatorname{tr} \vec{\nabla}\left(\frac{\partial B_{Z}}{\partial t}\right) \cdot \vec{v} p o l
$$

Practically, we propose to measure the gradient of the noise by measuring two orthogonal components by way of two perpendicular small figure- 8 loops along arbitrary directions $\mathrm{x}$ and $\mathrm{y}$, as depicted in Figure 4. It allows us to estimate the EM response of a virtual figure-8 loop in every direction:

$$
\begin{gathered}
\vec{\nabla}\left(\frac{\partial B_{z}}{\partial t}\right)=\left(\vec{\nabla}\left(\frac{\partial B_{z}}{\partial t}\right) \cdot \overrightarrow{u_{x}}\right) \overrightarrow{u_{x}}+\left(\vec{\nabla}\left(\frac{\partial B_{z}}{\partial t}\right) \cdot \overrightarrow{u_{y}}\right) \overrightarrow{u_{y}} \\
\vec{\nabla}\left(\frac{\partial B_{z}}{\partial t}\right)=\left(-\frac{\varepsilon_{x}}{\sqrt{2} L_{x}^{3} N t r_{x}} \operatorname{pol}_{x}\right) \overrightarrow{u_{x}}+\left(-\frac{\varepsilon_{y}}{\sqrt{2} L_{y}^{3} N t r_{y}} \operatorname{pol}_{y}\right) \overrightarrow{u_{y}}
\end{gathered}
$$


One should note that the " $x$ " and " $y$ " figure- 8 loops could be of different sizes, number of turns and not orthogonal. Thanks to the linearity of EM fields addition, equation 14 can be applied whatever the number (and nature) of magnetic noise sources.

The optimal direction for the eight-shape loop will then be indicated by the direction orthogonal to $\vec{\nabla}\left(\frac{\partial B_{z}}{\partial t}\right)$. If "x" and " $\mathrm{y}$ " are perpendicular, for instance northward and eastward respectively, then this best angle is obtained as:

$$
\varphi_{\text {best }}=-\operatorname{atan}\left(\frac{\vec{\nabla}\left(\frac{\partial B_{z}}{\partial t}\right) \cdot \overrightarrow{u_{x}}}{\vec{\nabla}\left(\frac{\partial B_{z}}{\partial t}\right) \cdot \overrightarrow{u_{y}}}\right)
$$

As a convention, we consider the polarity in the loops as positive clockwise in the northern square loop (respectively eastern loop). The best angle $\varphi_{\text {best }}$ is referred to the north, accounted positive eastward.

\section{Synthe tic cases study}

For the sake of illustration that the optimal direction may be tricky $t$, estimate even in a priori simple situations, we consider only ideal infinite straight powerlines over pure ${ }_{1}$, resistive environment $\left(c f . \mathrm{B}_{\mathrm{z}}\right.$ from equation 3) to simulate few synthetic cases. The emf in le igure-8 loop is the sum of the contributions of all powerlines (NTX):

With, the $\mathrm{k}^{\text {th }}$ powerline:

$$
\varepsilon(t) \approx-L^{3} \sqrt{2} N \operatorname{tr} * \operatorname{pol}\left(\left.\Gamma_{k \cdot 1}{ }^{T} T \bar{\nabla} \bar{V}\left(\frac{\partial B_{z}}{\partial t}\right)\right|_{k}\right) \cdot \vec{v}
$$

$$
\left.\vec{\nabla}\left(\frac{\partial B_{z}}{\partial t}\right)\right|_{k}(t)=-\omega_{k} I_{k} \cos \left(\omega_{k} t+\text { phase }_{k}\right){ }_{2 \pi}^{u_{0} \leqslant g n\left(\overline{M_{k} c} \cdot \overrightarrow{u_{\perp}^{k}}\right)} \frac{\overrightarrow{u_{\perp}^{k}}}{d_{k}^{2}}
$$

The synthetic case studies will consider different lay su involving a targeted figure-8 loop (namely RX $\mathrm{n}^{\circ} 1$, consisting of two square loops of $40 \mathrm{~m}$ sides) th an axis direction of $\mathrm{N} 45^{\circ}$, in the vicinity of two powerlines. Each powerline generates it $v$, n electromagnetic field depending on the power supply and demands on each line (amplite re, equency and phase of current). The synthetic time series have a $240 \mathrm{~ms}$ duration using a $18 \mathrm{kHz}$ s. mpling frequency.

Calculation of the noise gradient, by me $a^{-}$of two small orthogonal figure- 8 loops $\mathrm{RX} \mathrm{n}^{\circ} 2$ and $\mathrm{RX} \mathrm{n}^{\circ} 3$, (consisting of two square of $5 \mathrm{~m}$ sides "ith ' xis directions of $\mathrm{N} 0^{\circ}$ and $\mathrm{N}^{\circ} 0^{\circ}$ respectively), will allow to estimate the best and worst direction ${ }^{\circ} \mathrm{o} \mathrm{t}_{\mathrm{L}}$ f figure-8 loop (from equation 15).

The first layout consists in placing tin $\mathrm{fl}_{\mathrm{g} u \mathrm{u}} \mathrm{e}-8$ loops in between two parallel powerlines of direction $\mathrm{N} 30^{\circ}$ (Figure $4 \mathrm{a}$ ). For all different $\mathrm{c}_{\mathrm{a}}$ 'es aescribed in Table 1 , the best direction would be $\mathrm{N} 30^{\circ}$. 
a)

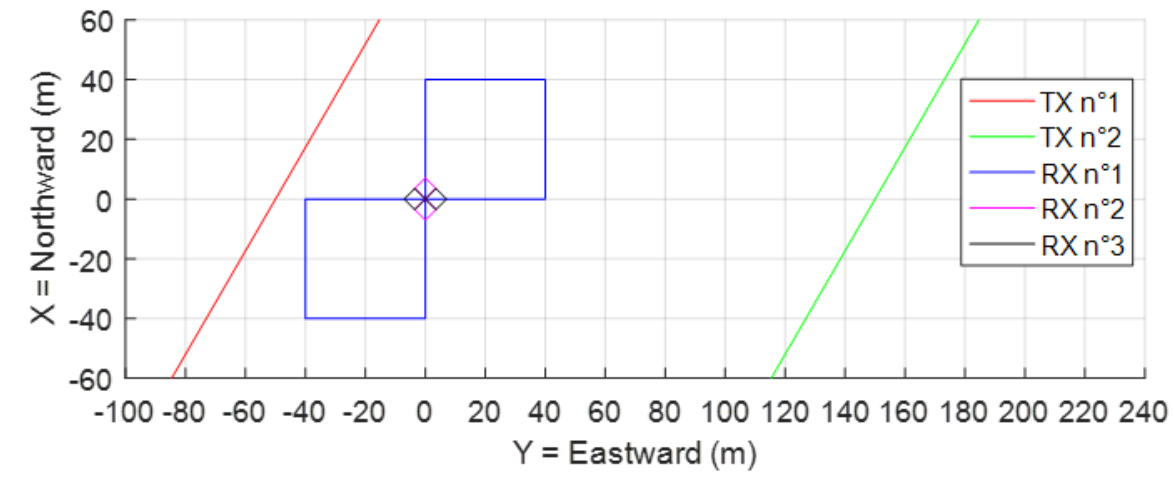

c)
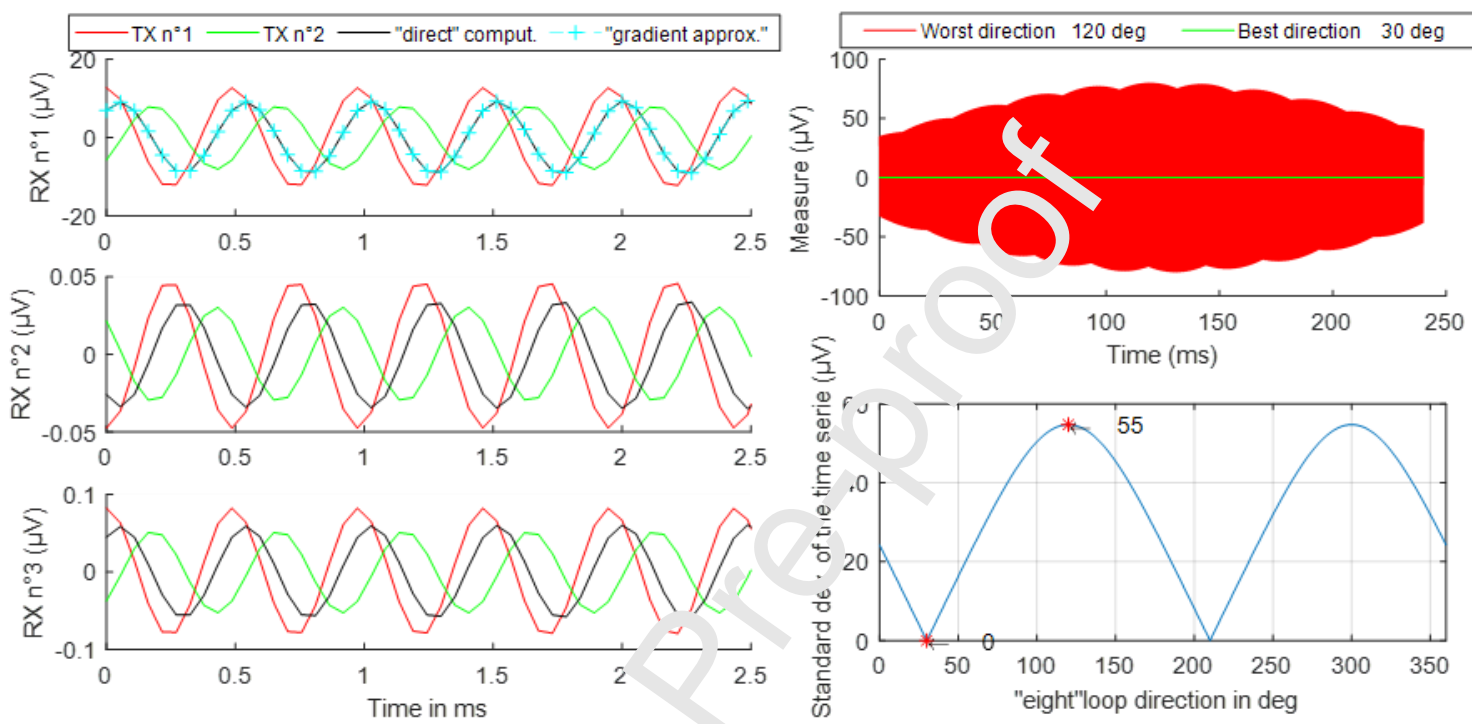

Figure 4. a) layout of the three figure- $8 \mathrm{~h}$ nd in-between two parallel powerlines oriented $\mathrm{N} 30^{\circ}$ (case $\mathrm{n}^{\circ}$ 5). b) zoom in the recorded signal in ${ }^{\circ} \cdot \mathrm{K}$. loops, due to powerline $\mathrm{TX}^{\circ} 1$ (red), $\mathrm{n}^{\circ} 2$ (green), the

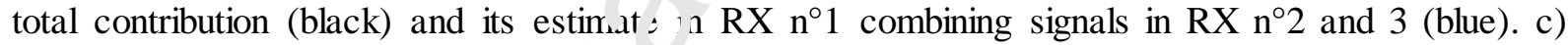
estimation of the $\mathrm{RX} \mathrm{n}^{\circ} 1$ signal an ${ }^{2}$ lutude along the best and worst direction $\left(30^{\circ}\right.$ and $120^{\circ}$ respectively) obtained from the star ${ }^{\top}$ ard deviation of the $\mathrm{RX} \mathrm{n}^{\circ} 1$ signal vs orientation (blue curve) estimated via the pair of small fiour -8 loops $\mathrm{RX} \mathrm{n}^{\circ} 2$ and $\mathrm{n}^{\circ} 3$ (red asterisks indicates min and max).

Table 1. Layout and various cirre ' parameters for the two parallel powerlines

\begin{tabular}{|l|c|c|c|c|c|c|c|c|c|}
\hline & \multicolumn{3}{|c|}{ Powerlin } & \multicolumn{3}{c|}{ Powerline TX n ${ }^{\circ}$} & $\begin{array}{c}\text { Best } \\
\text { angle }\left(^{\circ}\right)\end{array}$ \\
\hline Direction & $\begin{array}{c}\text { Current } \\
(\mathrm{mA},\end{array}$ & $\begin{array}{c}{ }^{\circ} \text { Fr } \\
\text { quency } \\
(\mathrm{Hz})\end{array}$ & $\begin{array}{c}\text { Phase } \\
\left({ }^{\circ}\right)\end{array}$ & Direction & $\begin{array}{c}\text { Current } \\
(\mathrm{mA})\end{array}$ & $\begin{array}{c}\text { Frequency } \\
(\mathrm{Hz})\end{array}$ & $\begin{array}{c}\text { Phase } \\
\left({ }^{\circ}\right)\end{array}$ & \\
\hline case 2 & $\mathrm{N} 30^{\circ}$ & 1 & 2050 & 0 & $\mathrm{~N} 30^{\circ}$ & 1 & 2050 & 0 & 30 \\
\hline case 3 & $\mathrm{N} 30^{\circ}$ & 1 & 2050 & 0 & $\mathrm{~N} 30^{\circ}$ & 2 & 2050 & 0 & 30 \\
\hline case 4 & $\mathrm{N} 30^{\circ}$ & 1 & 2050 & 0 & $\mathrm{~N} 30^{\circ}$ & 1 & 2053 & 0 & 30 \\
\hline case 5 & $\mathrm{N} 30^{\circ}$ & 1 & 2050 & 0 & $\mathrm{~N} 30^{\circ}$ & 1 & 2050 & 45 & 30 \\
\hline
\end{tabular}

The frequency difference generates a modulation of amplitude, which is clearly different on each RX loop. Using the gradient approximation, one can estimate precisely $\mathrm{RX}^{\circ} 1$ from $\mathrm{RX}{ }^{\circ} 2$ and 3 (Figure $4 \mathrm{~b}$, black versus blue signal). It allows to test the response for any orientation, providing the best and worst orientation (respectively $30^{\circ}$ and $120^{\circ}$ ). The noise amplitude variation with the loop orientation is displayed Figure $4 \mathrm{c}-$ bottom, through the standard deviation indicator.

We observed a small and constant ratio between the estimation of $\mathrm{RX} \mathrm{n}^{\circ} 1$ from $\mathrm{RX} \mathrm{n^{ \circ }} 2 \& 3$ and the directly computed $\mathrm{RX} \mathrm{n}^{\circ} 1$ signal. We estimate a constant correction coefficient (to be applied in eq. 13) based on the ratio of the standard deviation between $\mathrm{RX} \mathrm{n}^{\circ} 3$ (directly computed) and the result of eq. 13 and 14. The fit between the "directly computed" and the "gradient approximation" is illustrated in the zoom interval (0-2.5 ms) in Figure $4 \mathrm{~b}$. 
a)

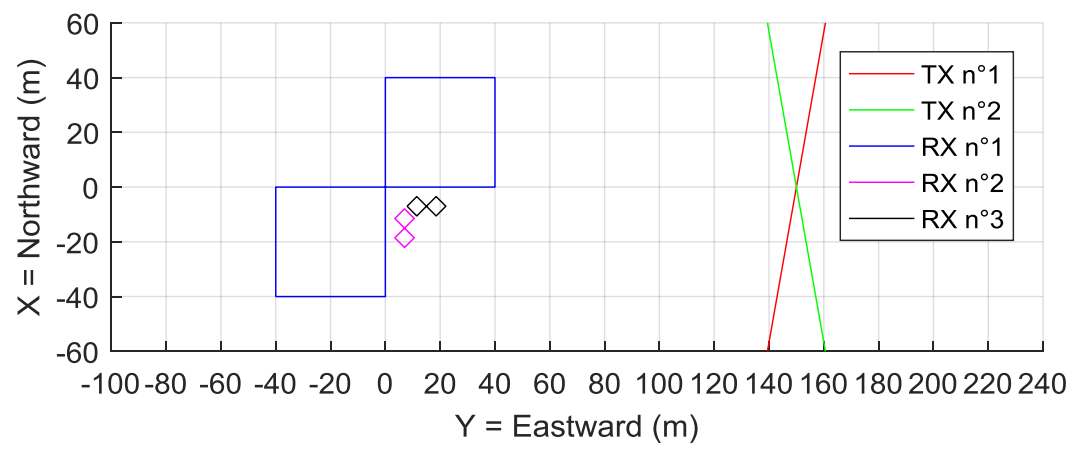

b)
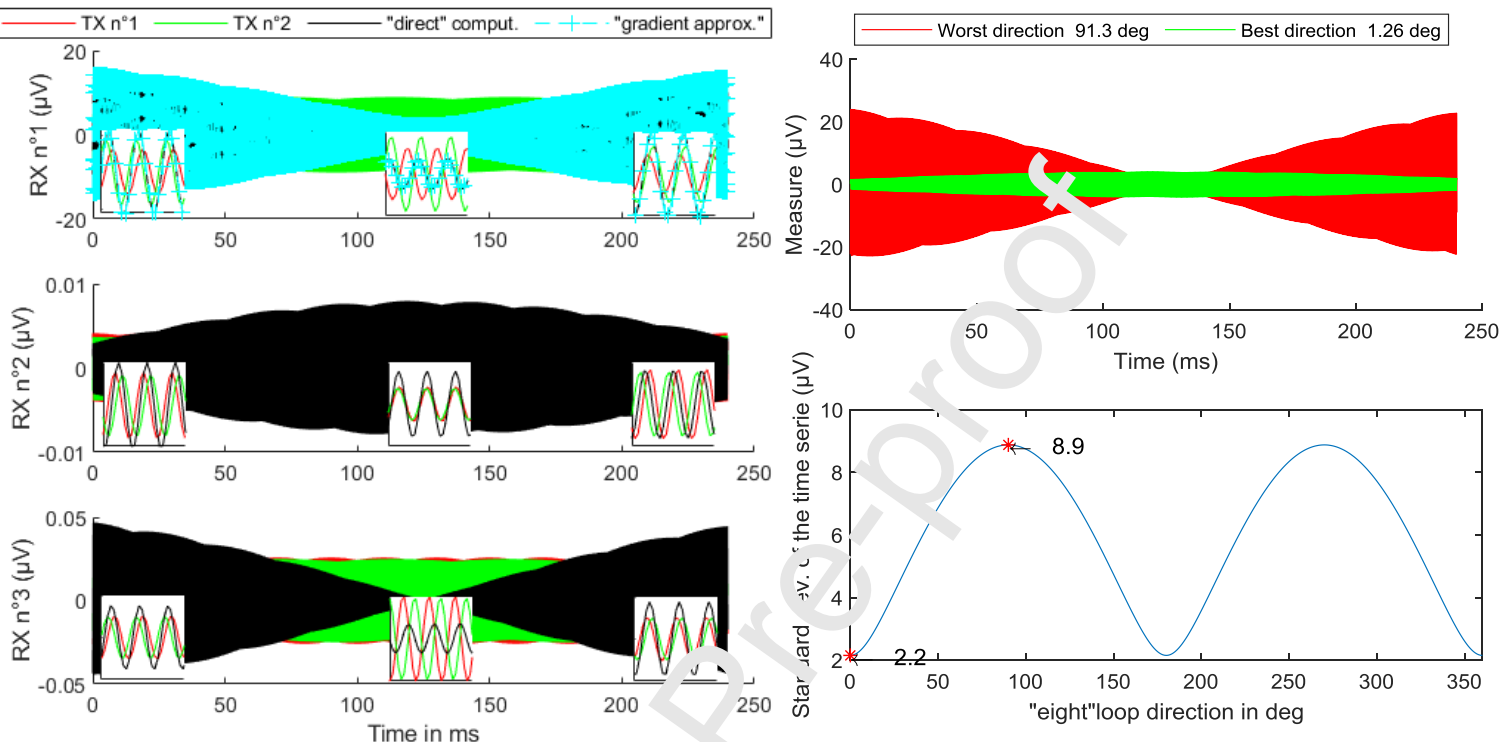

c)

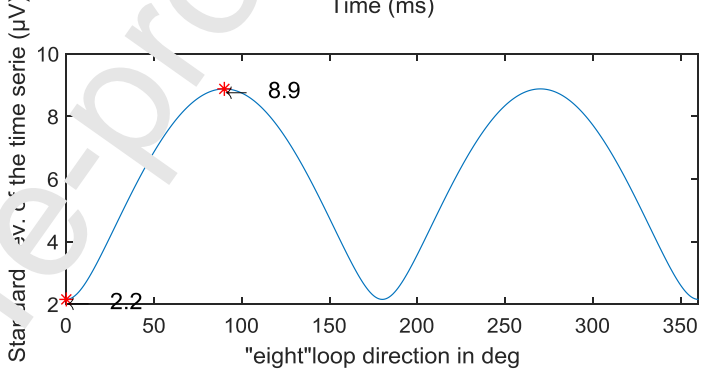

Figure 5. a) layout of the three figure- $8^{\prime}$ nops $15 \mathrm{v} \mathrm{m}$ away from two crossing powerlines (case $\mathrm{n}^{\circ} 10$ ), and $\mathrm{RX} \mathrm{n}^{\circ} 2$ \& 3 not centered on $\mathrm{RX} \mathrm{n}^{\circ} 1$. $\mathrm{L}$, the recorded signal in the RX loops due to powerline $\mathrm{TX}$ $\mathrm{n}^{\circ} 1$ (red), $\mathrm{n}^{\circ} 2$ (green) and the total $\mathrm{cr}^{\circ} \mathrm{nt}^{\circ}$ 'ion (black) and noise estimation in $\mathrm{RX} \mathrm{n}^{\circ} 1$ (blue), some zoom underline the various interfere $\ldots$ s. -) estimation of the $\mathrm{RX} \mathrm{n}^{\circ} 1$ signal amplitude along the best and worst direction $\left(1.3^{\circ}\right.$ and $91.3^{\circ}$ respectively) obtained from the standard deviation of the $\mathrm{RX} \mathrm{n}{ }^{\circ} 1$ signal vs orientation (blue curve) stinated via the pair of small figure- 8 loops $\mathrm{RX} \mathrm{n}{ }^{\circ} 2$ and $\mathrm{n}^{\circ} 3$ (red asterisks indicates min and max).

The second layout (depicted in Fig tre 5a) consists in placing the figure-8 loops $150 \mathrm{~m}$ away from two powerlines of different dirf stios s (respectively $-10^{\circ}$ and $+10^{\circ}$ ), with a symmetry ensuring a best angle of $0^{\circ}$ for case 6 (listea $\eta \ldots$ h, 2 ). To highlight the interferences of the powerlines in the recorded signals several zoom are included in Figure $5 \mathrm{~b}$ (using a magnifier glass tool modified after Zhivomirov, 2020). Despuc the strong modulations due to the powerlines geometries and current specificities, the gradient approximation allows to estimate the signal in $\mathrm{RX}^{\circ} 1$ from $\mathrm{RX} \mathrm{n}^{\circ} 2$ and 3. If these later loops where centered on $\operatorname{RX~}^{\circ} 1$ (as in figure 4), the estimation would be better and the best angle estimated exactly. We choose to display here a practical case, i.e. not centered, and show that the exact best angle is not obtain with the same accuracy $\left(1.3^{\circ}\right.$ instead of $0^{\circ}$ in this case $)$, but it provides a useful estimate. One may notice that the use of high resistance receivers instead of low impedance ones (as widely used in the field), the pair of figure- 8 loops could be set centered.

Table 2. Second layout and various current parameters for the two crossing powerlines

\begin{tabular}{|c|c|c|c|c|c|c|c|c|c|}
\hline & \multicolumn{4}{|c|}{ Powerline $\mathrm{TX} \mathrm{n}^{\circ} 1$} & \multicolumn{4}{|c|}{ Powerline $\mathrm{TX} \mathrm{n}^{\circ} 2$} & \multirow[b]{2}{*}{$\begin{array}{c}\text { Best } \\
\text { angle }\left(^{\circ}\right)\end{array}$} \\
\hline & Direction & $\begin{array}{c}\text { Current } \\
(\mathrm{mA})\end{array}$ & $\begin{array}{c}\text { Frequency } \\
(\mathrm{Hz})\end{array}$ & $\begin{array}{c}\text { Phase } \\
\left({ }^{\circ}\right)\end{array}$ & Direction & $\begin{array}{c}\text { Current } \\
(\mathrm{mA})\end{array}$ & $\begin{array}{c}\text { Frequency } \\
(\mathrm{Hz})\end{array}$ & $\begin{array}{c}\text { Phase } \\
\left({ }^{\circ}\right)\end{array}$ & \\
\hline case 6 & $\mathrm{~N}+10^{\circ}$ & 1 & 2050 & 0 & $\mathrm{~N}-10^{\circ}$ & 1 & 2050 & 0 & 0 \\
\hline case 7 & $\mathrm{~N}+10^{\circ}$ & 1 & 2050 & 0 & $\mathrm{~N}-10^{\circ}$ & 2 & 2050 & 0 & -3.5 \\
\hline case 8 & $\mathrm{~N}+10^{\circ}$ & 1 & 2050 & 0 & $\mathrm{~N}-10^{\circ}$ & 1 & 2053 & 0 & "0" \\
\hline case 9 & $\mathrm{~N}+10^{\circ}$ & 1 & 2050 & 0 & $\mathrm{~N}-10^{\circ}$ & 1 & 2050 & 45 & "0" \\
\hline case 10 & $\mathrm{~N}+10^{\circ}$ & 1 & 2050 & 0 & $\mathrm{~N}-10^{\circ}$ & 1 & 2053 & 45 & "0" \\
\hline
\end{tabular}


Among the case studies listed in table 2, case 6 and 7 have a unique and constant best direction, like all cases listed in table 1 . The best directions indicated in Table 2 are calculated with a centered pair of figure-8 loops. However, when the powerlines have different frequencies or dephasing (cases 8 to 10 for instance) interferences between their signals in the RX loops vary with time and the best angle is always changing. We highlight this time dependence through histogram of the best angle during a $240 \mathrm{~ms}$ (i.e. 4320 samples using $18 \mathrm{kHz}$ sampling frequency) record for case 8 (Figure 6a) where a 3 $\mathrm{Hz}$ frequency offset between the powerlines gives an average best angle around $0^{\circ}$. More commonly, close powerlines are part of the same distribution network and have the same regulated instantaneous frequency. Yet, their intensity and phase are linked to consumption on each line, which could be completely different. Case 9 illustrates a constant phase offset between the two powerlines and a best angle is largely dominating (see Figure 6b). Case 10 combines frequency and phase offsets which shows a best angle estimation of $0^{\circ}$ if the gradient is estimated at the center of $\mathrm{RX} \mathrm{n}^{\circ} 1$ (Figure $6 \mathrm{c}$ ) and of $1.3^{\circ}$ in the non-centered case (Figure $5 \& 6 \mathrm{~d}$ respectively).

a) Case 8

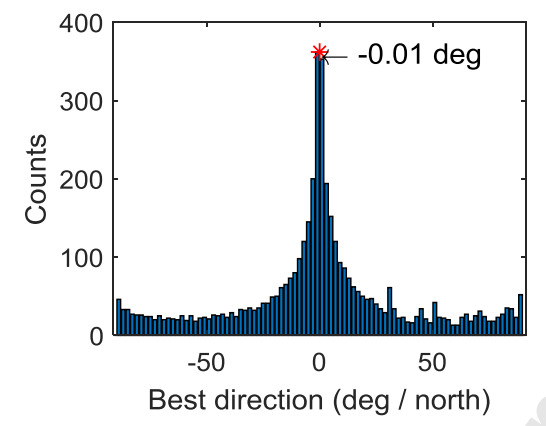

c) Case 10 centered

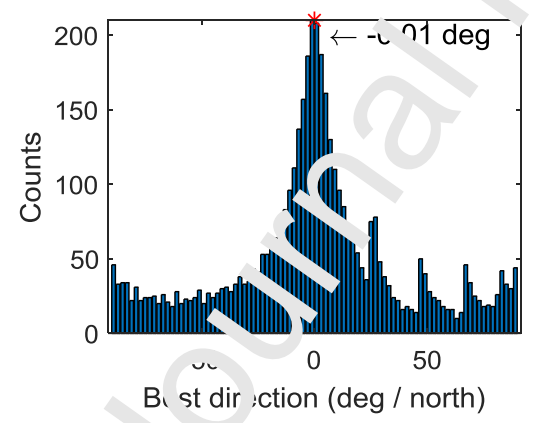

b) Case 9

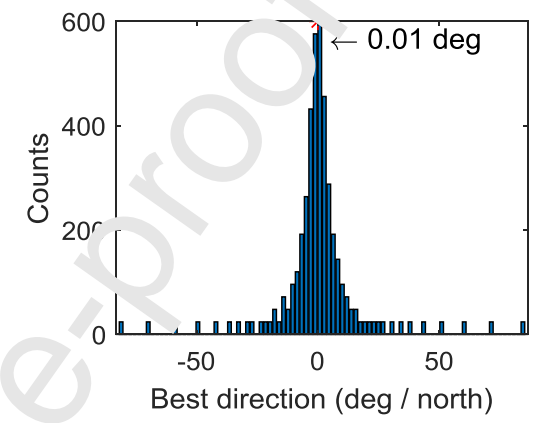

1) Case 10 (RX 2 \& 3 not centered on RX 1)

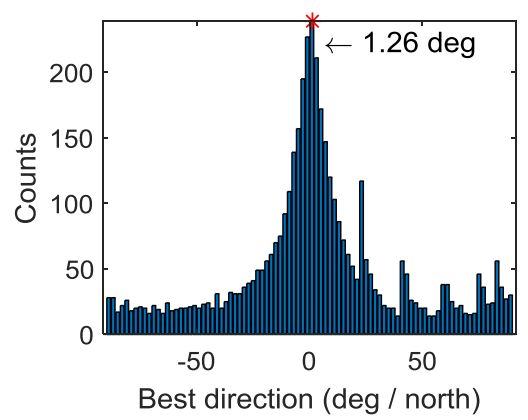

Figure 6. histogram of the sst direction estimated at each time sample (frequency sampling $18 \mathrm{kHz}$ ) during $240 \mathrm{~ms}$ using a ce $1 \ldots$ red pair of small figure-8 loops $(\mathrm{a}, \mathrm{b}, \mathrm{c})$ or not $(\mathrm{d})$.

The synthetic study has shown that interferences of signals due to powerlines with various phases and frequencies will generate a best direction for the figure-8 loop varying with time. Nevertheless, a stable best direction exists in most cases, encouraging the use of such noise characterization in the field before installing the MRS loop.

\section{Field study}

Whatever the number of powerlines, their locations and characteristics, the previous synthetic study suggests that a stable best and worst direction always exist. The issue is to find it before performing a MRS survey. A field study was conducted with various configurations close to the city of Strasbourg (France). The environment is a plain with a dense powerlines network (with high and low voltages), several small cities in the surrounding 3 kilometers, with mainly agricultural land use.

Measurements were performed with a multi-channel MRS system (Numis ${ }^{\text {poly }}$ ). As noise is always changing, to obtain clear conclusion, it is necessary to perform simultaneous measurements. We used 3 channels, each connected to a figure- 8 loop. $\mathrm{RX} \mathrm{n}^{\circ} 2$ and 3 are connected to 2 perpendicular small figure- 8 loops, $5 \mathrm{~m}$ side two turns, oriented North-South and East-West respectively. The channel RX $\mathrm{n}^{\circ} 1$ is used to measure the noise in a larger figure-8 loop of size suitable for MRS, two square loops of 
$20 \mathrm{~m}$ side 1 turn (see Figure 7). As the used system works with low impedance and tuned antennas, the distance between cables of the loops must not be too close and their orientation was kept away from parallel to minimize coupling in-between and avoid cross-talk. The pulse frequency $2025 \mathrm{~Hz}$ was chosen (close to the local Larmor frequency).

To be able to use a figure- 8 loop as a measurement of one component of the gradient of the noise in this direction, one need to respect a polarity convention of the square loops to know this direction. They are connected such as polarity is the same in the north square loop of $\mathrm{RX} \mathrm{n}^{\circ} 2$, in the east square loop of $\mathrm{RX} \mathrm{n}^{\circ} 3$ and in the north-east square of $\mathrm{RX} \mathrm{n}^{\circ} 1$ to respect the convention used in the previous synthetic study. It is equivalent to give a polarity to the figure-8 loop axis, which is easily understood when one considers that it is a proxy of a gradient measurement along its direction. Four sets of measurement were performed changing the direction of $\mathrm{RX} \mathrm{n}^{\circ} 1$, from $\mathrm{N}-45^{\circ}$ to $\mathrm{N}+90^{\circ}$.

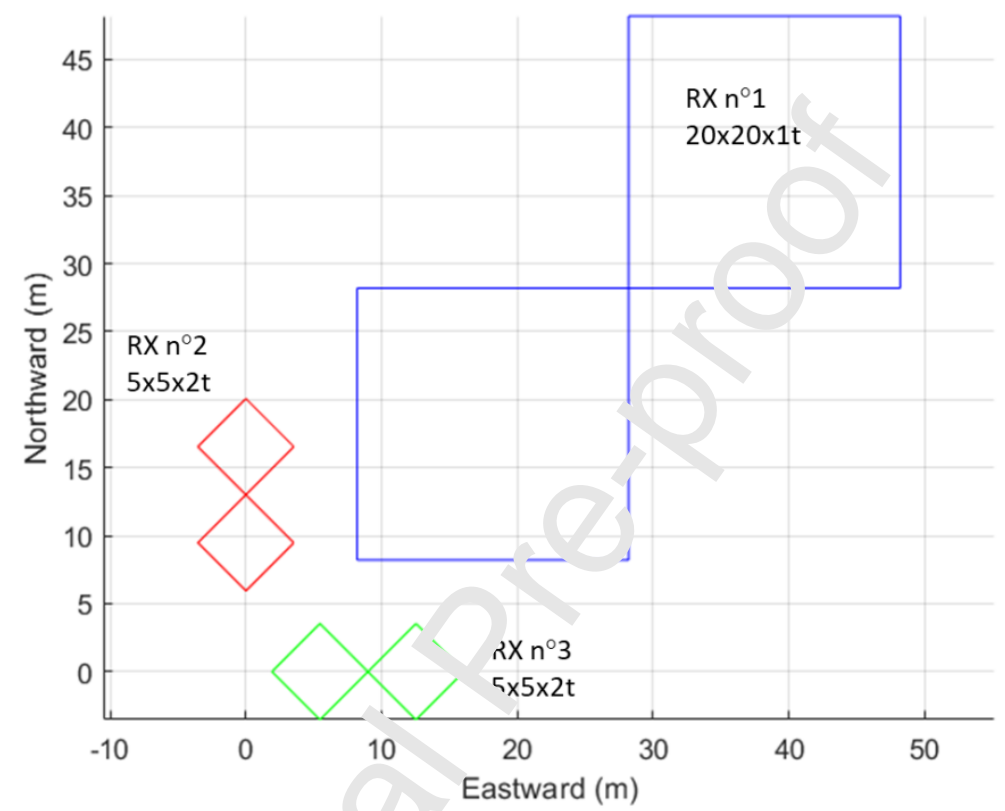

Figure 7. layout with three figure-8 lnnns in he test field

Following equation 15, the best cientation was calculated at each time sample of 100 records (commonly called stacks) of $244^{\prime}$ ms length sampled at $19.2 \mathrm{kHz}$. A band-pass filter $+/-200 \mathrm{~Hz}$ centered on $2025 \mathrm{~Hz}$ was app. ${ }^{-}$. The distribution of the best orientation during the $\sim 10$ minutes recording is depicted as a his distribution with a median $\mathrm{IIr}$ tion $\mathrm{N}-43^{\circ}$. The efficiency of the orientation filtering is symmetrical, as a best direction of ${ }^{\top} 13 ?^{\circ}$ Nould give the same result. Using this symmetry, we depict the best orientation distribution as a polar histogram in Figure $8 \mathrm{~b}$ (the color change indicates the symmetry used). Statistics are baseci...re on more than 400.000 time samples.
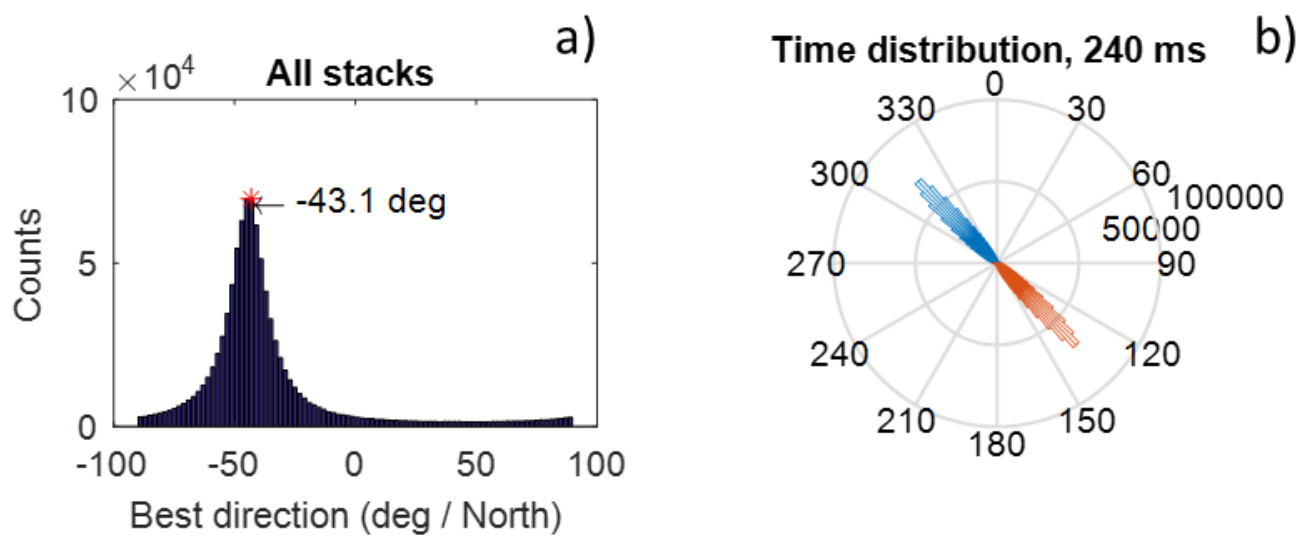

Figure 8. histogram of best direction over time: estimated at each time sample of 100 records (sampling frequency $19.2 \mathrm{kHz}$, duration $240 \mathrm{~ms}$ each) 
Based on this analysis, we selected one record $\left(n^{\circ} 101\right)$ and calculate the virtual response in time which would have been recorded for the best $\left(\mathrm{N}-43.1^{\circ}\right)$ and worst $\left(\mathrm{N}+46.9^{\circ}\right)$ directions. As depicted in Figure 9a, the standard deviation is lower all along the record for the best direction. We evaluated the effect of the figure- 8 loop azimuth for all orientations, repeated for all stacks and then derive the standard deviation of each records. The standard deviation and median value of the standard deviation for each orientation is depicted in Figure 9b. The best and worst angles are visible on both the median value and dispersion of the noise amplitude. The average standard deviation is reduced from $1100 \mathrm{nV}$ to $160 \mathrm{nV}$ in this case and the dispersion is reduced of a factor 7.

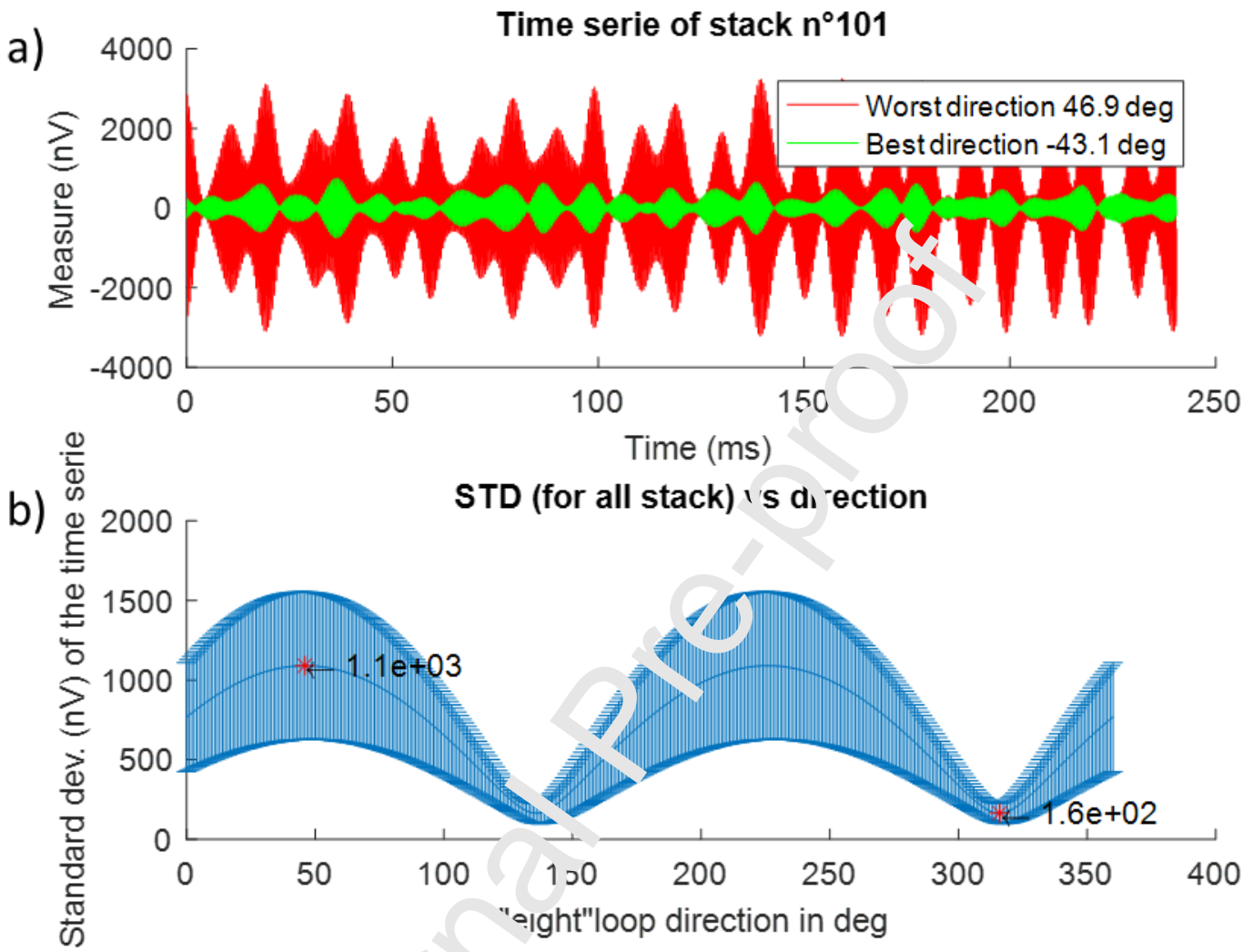

Figure 9. a) times series calculat ${ }^{\top}$ for the worst $\left(+46.9^{\circ}\right)$ and best orientation $\left(-43.1^{\circ}\right)$. b) evolution of the standard deviation calculated . mong 100 records for any orientation (from $0^{\circ}$ to $360{ }^{\circ}$ ).

One can wonder if the best $\mathrm{du}^{\prime} \mathrm{cti}$, $\mathrm{n}$ is dependent on the frequency. Fourier spectrum was calculated for each record. The best dire tion is then calculated applying eq. 15 on the real part of the Fourier coefficients for each fru ruc. . . Due to the short records duration $(240 \mathrm{~ms})$, the frequency bin is 4.2 Hz. This behavior of the be st orientation with frequency is displayed in Figure 10. One should note that the number of sampics is here the number of stacks (i.e. 100) which far less than in the time domain analysis presented in Figure 8 with the same dataset.

If we focus on the frequency $2025 \mathrm{~Hz}$ (close to the Larmor frequency and $25 \mathrm{~Hz}$ from the closest powerline harmonic), the histogram is almost flat and the median of the best orientation is $\mathrm{N}-42^{\circ}$ (Figure 10a and $\mathrm{b}$ ). When looking at the closest harmonics, the histogram shows a narrow maximum with median best direction of $\mathrm{N}-43^{\circ}$ for $2050 \mathrm{~Hz}$ (Figure 10d and e). Observation is similar for the other harmonics as it is displayed in polar plot for frequency $2000 \mathrm{~Hz}$ and $2100 \mathrm{~Hz}$ (Figure 10c and f) with best angles of $\mathrm{N}-35^{\circ}$ and $\mathrm{N}-49^{\circ}$ respectively. As expected, the powerlines harmonics present a clear directivity, here with a single best direction $\mathrm{N}-42^{\circ} \pm 10^{\circ}$. As the powerlines are the major source of noise here, it is coherent to find the same direction estimated broadband in the time domain. More surprising we observe that the residual noise outside the harmonics shows a weak but similar best direction. This is perhaps site-dependent, but we could propose two explanations. In the frequency domain analysis, using the simple Fourier transform some frequency leakage exists and could explain part of the observation. Another explanation would be that the powerlines large metallic infrastructure channelize the electric noise and make it directional. 

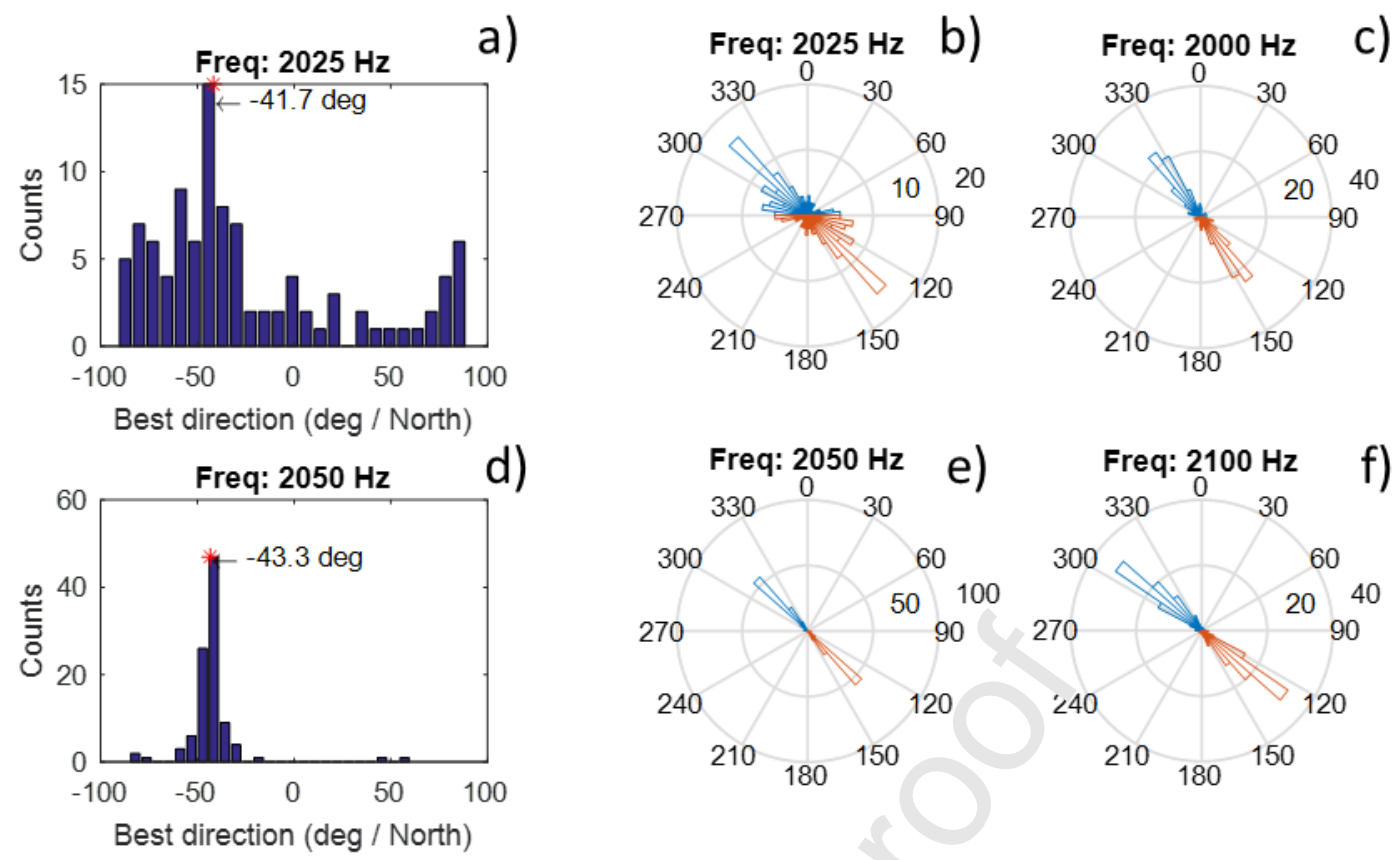

Figure 10. best orientation and frequency: histograms of $t^{2}-2$ s. orientation calculated for a selection of frequencies, using 100 records. Note that polar diag. $\urcorner \mathrm{ms}$ (right part) are another display of the histograms (left), especially for frequencies $2025 \mathrm{~Hz}$ and $20 \mathrm{i} \mathrm{Hz}$ where the same data are presented with the two displays.

A last test was performed to evaluate the best ori $n_{\mathrm{L}}$ tir.t effect of the measurements. The orientation of the large figure-8 loop $\mathrm{RX} \mathrm{n}{ }^{\circ} 1$ was chan $\ldots$. an $^{\circ}$ ing four successive recordings, $\mathrm{N}-45^{\circ}$ and $\mathrm{N}+45^{\circ}$ (close to the best and worst estimated rier ation respectively), and $\mathrm{N} 0^{\circ}$ and $\mathrm{N} 90^{\circ}$ which are intermediary directions. Results are presented i. Figure 11.

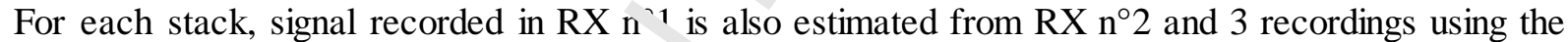
gradient approximation (with eq. 14). Tan he standard deviation is calculated from these $240 \mathrm{~ms}$ signals and compared in-between in i is ur: 11 (in red and blue respectively). For each case, the standard deviation of a virtual recci $a^{\prime} \cdot$ along $\mathrm{N}-43^{\circ}$ is also estimated (in green). First, one should note that the noise amplitude varir s "rring and in-between the experiments (which is in the nature of true noise). Secondly, the standa ${ }^{4}$ deviation of the gradient based approximation behaves like the recorded $\mathrm{RX} \mathrm{n}^{\circ} 1$, which was expc ted. Last and more significant, along the best direction $\left(\mathrm{N}-43^{\circ}\right)$, the standard deviation estimater is $c^{\circ}$ reased with a factor 6 if compared to the worst direction (NE), with

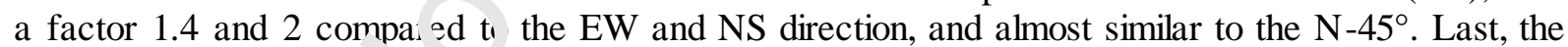
dispersion of the standa' ${ }^{\prime}$ ueviation is also clearly reduced along the best direction in a similar proportion. 

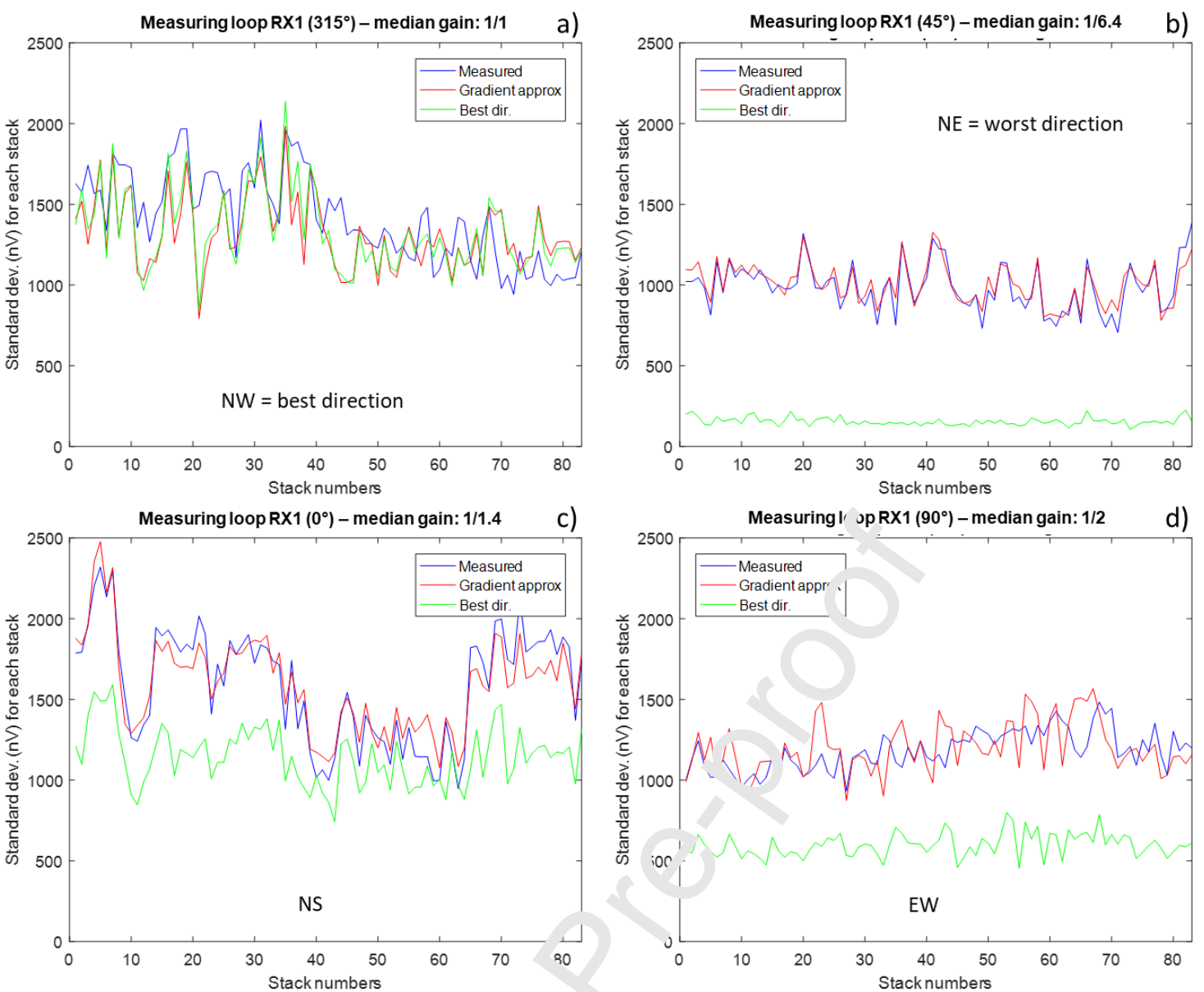

Figure 11. in-situ validation of figure-8 rientation efficiency: the two small figure- 8 loops are fixed NS and EW, but the large 20x20m figure- $\gamma$ ' nop RX n ${ }^{\circ} 1$ is rotated from NW (a) to EW (d) with a $45^{\circ}$ step. The measured noise (blue) is $c \mathrm{c}^{\prime} \cdot \mathrm{a}^{\circ} \mathrm{d}$ with the gradient estimation (red) and the theoretical response in the best direction (green)

To illustrate that the gain in standa. $\mathrm{f}$ de viation along each single records is also obtained in the final stack signal, we compare in Figul 12 ine stack of 100 records for the measuring loop RX $\mathrm{n}^{\circ} 1$ oriented NE (along the worst direction) with the stacked approximation for this loop through gradient approach using the two small figure- $8 \log _{1} c$, NS and EW). This illustrates that the reconstructed noise is a good estimator. It is also depic ted vhat would have been obtained for a measurement along the best direction $\left(-43^{\circ}\right)$. The gal. ol the standard deviation is similar to the average gain obtained at each records (see Figure 11b). If we draw the same results when the measuring MRS loop is oriented NW, no gain is obtained (Figure 11a).

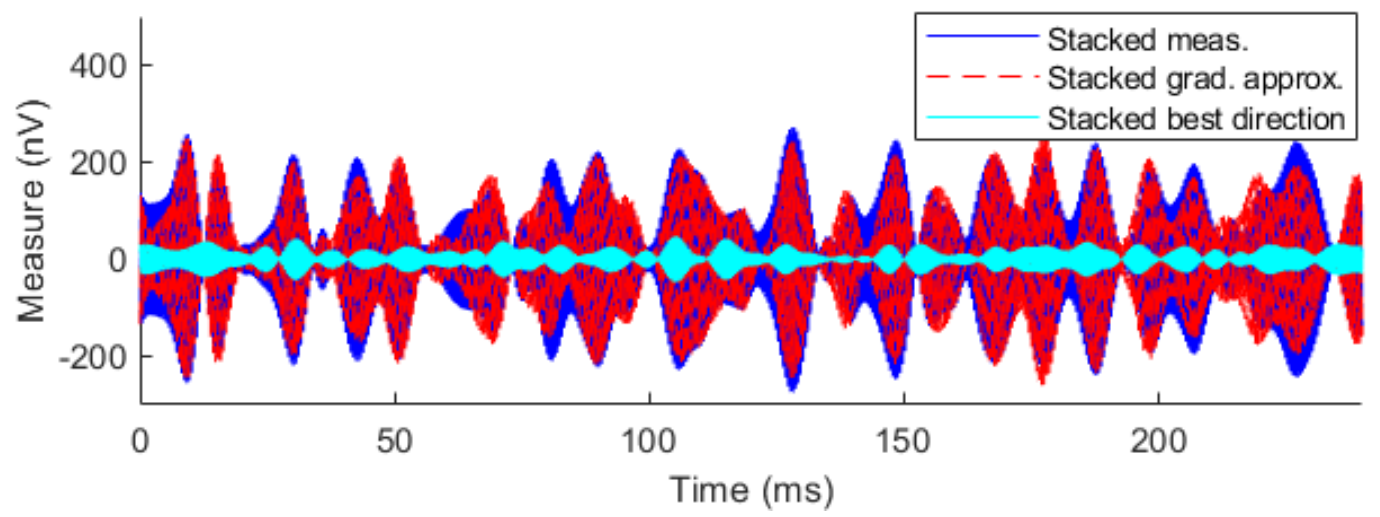


Figure 12. stack of 100 records for the measuring loop (blue) oriented NE along the worst direction, approximation in this loop through gradient approach (red) and result that would have been obtained along the best direction (cyan)

\section{Discussion}

Some other tests were performed in-situ. For instance, changing the direction of the two perpendicular small figure- 8 loops does not change the estimated best direction. The layout being easy to handle, it proves to be a fast and efficient way to evaluate the spatio-temporal behavior of the noise before installing a large MRS loop. This information is also helpful to install non figure-8 loops with reference loops as it provides insight where to install references loops in various noise conditions. For instance, two references loops (square or circular loops) aligned along the "best figure- 8 direction" are expected to have the same response: we would suggest installing them perpendicularly to this direction to improve the chance that they provide independent information.

In our synthetic study, we show that figure of eight loops always provide a better signal to noise ratio than square loops whatever the orientation chosen. It is particularl interesting when the noise level varies strongly and can saturate the recording device. In particular, a the figure- 8 loop reduces the amplitude of noise before digitalization of signals, it is useful / ne some numerous spikes (high amplitude short duration perturbations) happen.

Practically, as noise is always changing within a few tens of $\mathrm{m}$ llise onds, the noise reduction is never $100 \%$ and observed improvement when using figure-8 loops $1 \mathrm{~s}_{\mathrm{s}} . \mathrm{d}$ l to noise ratio is in the range of 2 to 10 as reported in Bernard (2007). This improvement crmbu 'ed to square loops is obtained at the recording step, and can be combined with various casca 'e fi ering strategies. The whole processing can be applied to a subset of 100 stacks for instance, pe for ned as pure noise records without pulse emitted and no delay between repeated measuremer is 'no need to wait for the protons spins to come back to equilibrium). Within less than 10 minutes if ecords, one can evaluate in advance MRS sounding quality and duration of MRS measuramt. + (i.e. the number of stacks).

On synthetic data and with real data, a calit ati $n$ coefficient has been used to improve the amplitude estimation in the large loop from the pair of s. all figure-8 loops using eq. 13 and 14. Practically, the gradient approximation of the noise in the recording loop calculated from $\mathrm{RX} \mathrm{n}^{\circ} 2$ and 3 (red curves in Figure 11) is normalized to fit the real nois amplitude measured in loop $n^{\circ} 1$ (blue curves in Figure 11). This coefficient is constant and $n$ ar cupend on the site conditions (distance to the powerlines). This point has no consequences in $f^{\prime \prime n g}$ ule best orientation and filtering strategy but is needed for a more precise evaluation of noise $a n_{1}$ litude.

Using a multi-channel equipment oula suggest to use the pair of small figure-8 loops as a reference signal to filter the large loop. 't this stage of experiment, direct subtraction of gradient based estimation is no more efficient tha a remote filtering using transfer function in the frequency domain. Interestingly, people who tten pted to filter figure-8 large loops with small square or circular loops have experienced a we $a^{-} i_{n_{r}}$. ovement. We observed on field data that filtering a large figure-8 loop by a small figure- 8 loop is I ore efficient than using a simple loop, which could be combined with the use of an optimal direction. But, as always with reference filtering, the coherency between reference and measuring loop is decreasing with distance, and one should deal with the paradox not to be too close and record MRS signal in the reference loop. Additional testing in various field conditions are to be done and the link with reference filtering opens several strategies to be investigated in future work.

\section{Conclusions}

Figure-of-eight shape loops are used for long time as they practically proved to be efficient in noisy environment despite a reduced investigation depth compared to a square loop with the same length of cable. They are particularly interesting as the noise reduction is obtain before digitalizing and it could be added to many other filtering strategies.

It was demonstrated how the response of a large figure- 8 loop can be estimated from the horizontal gradient of the magnetic field vertical component. This later can be measured with a pair of small figure-8 loops, which can be quickly installed in the field. Numerically, the further are the powerlines, the more precise is this estimation. At a distance larger than three loop lengths, the error is less than $1 \%$.

If the two small figure-8 loops are perpendicular, it is easy to estimate the best orientation for measuring MRS with a large figure-8 loop. On synthetic models considering several powerlines, 
parallel or not, with similar or different currents (frequency, amplitude and phase differences) resulting in time modulation of the noise, a single and robust best direction always exist and can be evaluated. An accuracy of $\pm 5^{\circ}$ is sufficient to be in the optimal direction.

The methodology was applied to field data and confirmed the main results. A single stable orientation was estimated from a pair of small figure- 8 loops and allowed to reduce the mean and the standard deviation of noise in a large figure-8 loop. This spatio-temporal characterization is quick to perform instead of mapping the noise amplitude with a small sensor loop. Installation of a pair of orthogonal 5 $\mathrm{m}$ figure- 8 loops is a matter of minutes, and $10 \mathrm{~min}$ recordings allows to estimate the acquisition parameters for a large figure-8 MRS loop (best orientation, number of stacks, etc..) or decide to abandon the site if a sufficient signal to noise ratio appears unrealizable.

\section{Acknowledgements}

The post-doctoral position of C. Jodry was funded by the Idex-Unistra program W16RPD19. The research work on noise reduction is funded by the french national research agency through the Exciting project $\mathrm{n}^{\circ}$ ANR-17-CE06-0012-01.

Authors are grateful to S. Penz previously at BRGM, who collat orated in 2014 on the very first development of the software MRSprocess and powerlines instantanes is frequency monitoring during a post-doctoral position funded by the project EQUIPEX CRITEX A^ R-11-EQPX-0011).

Authors thank Dr S. Costabel and an anonymous reviewer for th in constructive comments, which helped improve the document

\section{Bibliography}

Behroozmand, A. A., Keating, K. and Auken, E. $\left(\angle 0_{1} 5\right)$ 'A Review of the Principles and Applications of the NMR Technique for Near-ace Characterization', Surveys in Geophysics, 36, pp. 27-85. doi: 10.1007/s10712-n14-9304-0.

Behroozmand, A. A., Auken, E., Fiandaca ¿ and Rejkjaer S. (2016) 'Increasing the resolution and the signal-to-noise ratio $\mathrm{o}^{r}$, ag atic resonance sounding data using a central loop configuration', Geophysical Jo.rral International, 205, pp. 243-256. doi: 10.1093/gji/ggw004.

Bernard, J., (2007). 'Instruments and felci work to measure a Magnetic Resonance Sounding', Boletín Geológico y Minero, 118 (3), /5,-472, ISSN: 0366-0176

Chalikakis, K., Nielsen, M. R. a. d Lugchenko, A. V (2008) 'MRS applicability for a study of glacial sedimentary aquifers in Cenıral Jutland, Denmark', Journal of Applied Geophysics. Elsevier B.V., 66, pp. 176-18 i. doi: 10.1016/j.jappgeo.2007.11.005.

Chen, W., Ma, H., Yu $₹$ and Zhang, H. (2016) 'SVD-based technique for interference cancellation and nois $r$ dur ion in NMR measurement of time-dependent magnetic fields', Sensors (Switzerland), 16 3). doi: 10.3390/s16030323.

Costabel, S. and Müller-Petke, M. (2014) 'Despiking of magnetic resonance signals in time and wavelet domains', Near Surface Geophysics, 12(2016), pp. 185-197. doi: 10.3997/18730604.2013027.

Costabel, S. (2019), Noise analysis and cancellation for the underground application of magnetic resonance using a multi-component reference antenna - Case study from the rock laboratory of Mont Terri, Switzerland, Journal of Applied Geophysics, 169, 85 - 97.

Dalgaard, E., Auken, E. and Larsen, J. J. (2012) 'Adaptive noise cancelling of multichannel magnetic resonance sounding signals', Geophysical Journal International, 191(1), pp. 88100. doi: 10.1111/j.1365-246X.2012.05618.x.

Dalgaard, E., Christiansen, P., Larsen, J.J. and Auken E. (2014) 'A temporal and spatial analysis of anthropogenic noise sources affecting SNMR', Journal of Applied Geophysics. Elsevier B.V., 110, pp. 34-42. doi: 10.1016/j.jappgeo.2014.08.009.

Dalgaard, E. and Auken, E. (2016) 'Enhancing SNMR model resolution by selecting an 
optimum combination of pulse moments, stacking and gating', Near Surface Geophysics, pp. 1-11. doi: 10.3997/1873-0604.2016004.

Davis, A. C., Dlugosch, R., Queitsch, M., Mc Nae, J.C., Stolz, R. and Müller-Petke, M. (2014) 'First evidence of detecting surface nuclear magnetic resonance signals using a compact B-field sensor', Geophysical Research Letters, 41, pp. 4222-4229. doi: 10.1002/2014GL060150.

Díaz-Curiel, J. Biosca, B., Arevalo, L and Plata, J.L. (2011) 'Development of field techniques for improving MRS quality in shallow investigations', Near Surface Geophysics, 9(2), pp. 113-121. doi: 10.3997/1873-0604.2010072.

Dlugosch, R., Mueller-Petke, M., Günther T., Costabel, S. and Yaramanci, U. (2011) 'Assessment of the potential of a new generation of surface nuclear magnetic resonance instruments', Near Surface Geophysics, 9(2), pp. 89-102. doi: 10.3997/1873-0604.2010063.

Ghanati, R., Hafizi, M. K. and Fallahsafari, M. (2016) 'Surfac nuclear magnetic resonance signals recovery by integration of a non-linear decom osn on method with statistical analysis', Geophysical Prospecting, 64(2), pp. 489-504. do: 1し.:111/1365-2478.12296.

Girard, J.-F, Penz., S., Texier, A., Baltassat, J-M. and I ey.' „nko, A. (2015) 'Noise removal in MRS applications: field cases and filtering strate cies' in MRS workshop $2015 / 6^{\text {th }}$ International workshop on Magnetic Resonance, Jur. 20 5, Aarhus, Denmark.

Grombacher, D. and Knight, R. (2015) 'The impart of oif-resonance effects on water content estimates in surface nuclear magnetic resonance' je sphyscis, 80(6), pp. E329-E342.

Grunewald, E., Grombacher, D. and W'a', ?. (2016) 'Adiabatic pulses enhance surface nuclear magnetic resonance measuremeı a ld survey speed for groundwater investigations', Geophysics, 81(4), pp. WB85-WB96. doi: li 1190/geo2015-0527.1.

Hein, A., Larsen, J. J. and Parsekinn, A. D. (2017) 'Symmetry based frequency domain processing to remove harmonic $\mathrm{n}_{\mathrm{\prime}}$, ise from surface nuclear magnetic resonance measurements', Geophysical s.rnal International, 208(2), pp. 724-736. doi: 10.1093/gji/ggw433.

Hertrich, M., Braun, M. anc' Yaramanci, U. (2005) 'Magnetic resonance soundings with separated transmitter and reci ive: loops', Near Surface Geophysics, pp. 141-154.

Ibrahim, M., Pardi, C I., Brr wn, T.W.C. and Mc Donald, P.J. (2018) 'Active elimination of radio frequency interfere. $2 e$ for improved signal-to-noise ratio for in-situ NMR experiments in strong magnetic fielả sradients', Journal of Magnetic Resonance. Elsevier Inc., 287, pp. 99-109. doi: 10.1016/j.jmr.2018.01.002.

Jiang, C., Lin, J., Duan, Q., Sun, S. and Tian, B. (2011) 'Statistical stacking and adaptive notch filter to remove high-level electromagnetic noise from MRS measurements', Near Surface Geophysics, 9(5), pp. 459-468. doi: 10.3997/1873-0604.2011026.

Jiang, C., Müller-Petke, M. and Yaramanci, U. (2015) 'Magnetic resonance tomography using elongated transmitter and in-loop receiver arrays for time-efficient 2-D imaging of subsurface aquifer structures', Geophysical Journal International, 200(2), pp. 824-836. doi: $10.1093 / \mathrm{gij} / \mathrm{ggu} 434$.

Kass, M. A., Irons, T.P., Behroozmand, A.A., Grombacher, D. and Bloss, B.R. (2017) 'Surface nuclear magnetic resonance with compact multicomponent receivers', in 23rd European Meeting of Environmental and Engineering Geophysics, 3-7 September, Malmö, Sweden, Abstract Tu23A07. 
Kremer, T., Larsen, J. J. and Nguyen F. (2019) 'Processing harmonic EM noise with multiple or unstable frequency content in surface NMR surveys', Geophysical Journal International, 219, pp. 753-775. doi: 10.1093/gji/ggz307.

Larsen, J. J., Dalgaard, E. and Auken, E. (2013) 'Noise cancelling of MRS signals combining model-based removal of powerline harmonics and multichannel Wiener filtering', Geophysical Journal International, 196(2), pp. 828-836. doi: 10.1093/gi/ggt422.

Larsen, J. J. and Behroozmand, A. A. (2016) 'Processing of surface-nuclear magnetic resonance data from sites with high noise levels', Geophysics, 81(4), pp. WB75-WB83. doi: 10.1190/GEO2015-0441.1.

Larsen, J. J. (2016) 'Model-based subtraction of spikes from surface nuclear magnetic resonance data', Geophysics, 81(4), pp. WB1-WB8. doi: 10.1190/GEO2015-0442.1.

Legchenko, A. V and Valla, P. (2002) 'A review of the basi principles for proton magnetic resonance sounding measurements', Journal of Applied Geop'vics, 50, pp. 3-19. doi: 10.1016/S0926-9851(02)00127-1.

Legchenko, A. V and Valla, P. (2003) 'Removal of pov er-line harmonics from proton magnetic resonance measurements', Journal of Applied Gishics, 53(2-3), pp. 103-120. doi: 10.1016/S0926-9851(03)00041-7.

Legchenko, A. V (2005) 'Improved modelling of th- magnetic resonance signal in the presence of shallow aquifers', Near Surface Georh $v_{\text {sics, }}$ (3), pp. 121-130.

Legchenko, A. V (2007) 'MRS measureme at a id inversion in presence of EM noise', Boletin Geologico y Minero, 118(3), pp. 4;

Legchenko, A. Ezersky, M., Girard, I.F., Baltassat, J-M. and Boucher, M. (2008) 'Interpretation of magnetic resonanc soundıngs in rocks with high electrical conductivity', Journal of Applied Geophysic Alsevier B.V., 66(3-4), pp. 118-127. doi: 10.1016/j.jappgeo.2008.04.002.

Legchenko, A. V (2013) Magne ic nisonance Imaging for groundwater. ISTE Ltd and John Wiley \& Sons, Inc, ISBN: 978 1-843-21568-9

Liebich, D.A., Legchenko, A., Haeni, F.P. and Portselan, A. (1994) 'Surface Nuclear magnetic resonance exr - in its to detect subsurface water at Haddam Meadows, Connecticut', in Pros 'ecing of the $7^{\text {th }}$ Symposium on the Application of Geophysics to Engineering and Enviror. nental Problems, pp. 717-736.

Lin, T., Yang, Y., Teng, F. and Müller-Petke, M. (2018) 'Enabling surface nuclear magnetic resonance at high-noise environments using a pre-polarization pulse', Geophysical Journal International, 212(2), pp. 1463-1467. doi: 10.1093/gij/ggx490.

Liu, L., D. Grombacher, E. Auken, and J.J. Larsen, (2018), 'Removal of co-frequency powerline harmonics from multichannel surface NMR data', IEEE Geoscience and Remote Sensing Letters, 15, no. 1, 53-57.

Liu, L., D. Grombacher, E. Auken, and J.J. Larsen, (2019), 'Complex envelope retrieval for surface nuclear magnetic resonance data using spectral analysis', Geophysical Journal International, ggz068, doi:10.1093/gji/ggz068.

Müller-Petke, M., Walbrecker, J. O. and Knight, R. (2013) 'The inversion of surface-NMR data for improved aquifer characterization', Geophysics, 78(6), pp. EN83-EN94. doi: 10.1190/geo2013-0035.1.

Müller-Petke, M. and Costabel, S. (2014) 'Comparison and optimal parameter settings of 
reference based harmonic noise cancellation in time and frequency domains for surfaceNMR', Near Surface Geophysics, 12(2), pp. 199-210. doi: 10.3997/1873-0604.2013033.

Müller-petke, M., Braun, M., Hertrich, M., Costabel, S. and Walbrecker, J. (2016) 'MRSmatlab - A software tool for processing, modeling, and inversion of magnetic resonance sounding data', Geophysics, 81(4), pp. WB9-WB21. doi: 10.1190/geo2015-0461.1.

Plata, J. and Rubio, F. (2002) 'MRS experiments in a noisy area of a detrital aquifer in the south of Spain', Journal of Applied Geophysics, 50, pp. 83-94.

Radic, T. (2006) 'Improving the Signal-to-Noise Ratio of surface NMR data due to the remote reference technique', in 12th European Meeting of Environmental and Engineering Geophysics.

Radic, T. (2009) 'Improving the progress of small-scale magnetic resonance sounding (mrs) measurements', in 15th EAGE European Meeting of En ironmental and Engineering Geophysics, poster.

Sternberg, B. K. (2010) 'The variability of naturally occuring nagnetic field levels: $10 \mathrm{~Hz}$ to $8 \mathrm{kHz}$, Geophysics, 75(6), p. F187. doi: 10.1190/1.34 36.'

Strehl, S. (2006) Development of strategies for impi, vea filtering and fitting of SNMRsignals. Technical University of Berlin. A alk hle at: https:/www.geophysik.tuberlin.de/fileadmin/a36321500/Diplomarbeiten/Strehl.p if.

Trushkin, D. V, Shushakov, O. A. and Legche IK', A. V (1994) 'The potential of a noisereducing surface NMR groundwater surveys \& the earth's magnetic field', Geophysical Prospecting, 42, pp. 855-862.

Walsh, D. O. (2008) 'Multi-channel suri e NMR instrumentation and software for 1D/2D groundwater investigations', Journal ef Applıed Geophysics. Elsevier B.V., 66, pp. 140-150. doi: 10.1016/j.jappgeo.2008.03.006.

Yang, C.-F., Lai, G.G., Su, C-T. anc F uang, H.M. (2013) 'Mitigation of magnetic field using three-phase four-wire twisted cibles', International Transactions on Electrical Energy systems, 23, pp. 13-23. doi: 1C 100_'etep.636

Zhivomirov, H. (2020). 'Intera :tive 2D Plot Magnifier with Matlab', Matlab Central File Exchange, $\quad$ https $\%$ '. wr.mathworks.com/matlabcentral/fileexchange/65561-interactive-2dplot-magnifier-with- $m$ ' $t$ tla'

\section{Annex}

Annex 1 -Comments on the intensity of the current in the powerlines

According to the EN 50160 standard which define the quality of the distributed current in France on the public network, in the sinusoidal form and a fundamental frequency of $50 \mathrm{~Hz}$, the impair harmonic's amplitude follow the law of the following type Voltage $_{\text {harmonic }}(k)=0.2+0.5 * \frac{25}{k}$ in percent. Considering that the intensity is proportional to the voltage, if the intensity of the fundamental is of $1 \mathrm{~A}$, the $41^{\text {th }}$ harmonics (i.e., $2050 \mathrm{~Hz}$ ) will have an intensity of $0.005 \mathrm{~A}$. Hence the choice of the value $1 \mathrm{~mA}$ at $2050 \mathrm{~Hz}$ in the synthetic models to have a reasonable order of magnitude for the low voltage powerlines. Note that the CEI 61000-3-2 standard limits the emitted current at $50 \mathrm{~mA}$ for the $41^{\text {th }}$ harmonics.

Annex 2 - Two calculations of the emf induced by an ideal powerline

Comparison of the emf induced by a powerline in a large eight shape loop estimated from the $B_{z}$ gradient or from the emf difference between two square loops.

The vertical component of the magnetic field generated by an ideal infinite straight powerline in a resistive environment is:

$B_{Z}(t)= \pm \frac{\mu_{0} I(t)}{2 \pi r_{\perp}}$ 
Considering the notations in Figure 2.

i) Using the gradient of $B_{z}$, then:

$$
\begin{gathered}
\overrightarrow{\nabla B_{Z}}=\frac{\partial B_{z}}{\partial r_{\perp}} \overrightarrow{u_{\perp}}=-\frac{\mu_{0} I}{2 \pi} \frac{\operatorname{sign}\left(\overrightarrow{M C} \cdot \overrightarrow{u_{\perp}}\right)}{r_{\perp}^{2}} \overrightarrow{u_{\perp}} \\
\text { With } \overrightarrow{C_{2} C_{1}}=\sqrt{2} L \vec{v} \quad \text { and } \quad \overrightarrow{u_{\perp}} \cdot \vec{v}=-\sin \varphi \\
\overrightarrow{\nabla B_{Z}} \cdot \overrightarrow{C_{2} C_{1}}=-\frac{\mu_{0} I}{2 \pi} \frac{\operatorname{sign}\left(\overrightarrow{M C} \cdot \overrightarrow{u_{\perp}}\right)}{d^{2}} \sqrt{2} L \overrightarrow{u_{\perp}} \cdot \vec{v}
\end{gathered}
$$

And following eq. 11:

$$
\varepsilon=-\frac{\mu_{0}}{2 \pi} \frac{d I}{d t} \operatorname{sign}\left(\overrightarrow{M C} \cdot \overrightarrow{u_{\perp}}\right) \operatorname{pol} S \frac{\sqrt{2} L}{d^{2}} \sin \varphi
$$

ii) Using the difference between two square loops and the flux estimated using the value of $B_{z}$ at the center of each loop:

$$
\begin{gathered}
\varepsilon=\varepsilon_{1}+\varepsilon_{2} \\
=-\frac{\mu_{0}}{2 \pi} \frac{d I}{d t}\left[\operatorname{sign}\left(\overrightarrow{M C_{1}} \cdot \overrightarrow{u_{\perp}}\right) \operatorname{pol}_{1} \frac{S_{1}}{r_{1}}+\operatorname{sign}\left(\overrightarrow{M C_{2}} \cdot \overrightarrow{r_{1}}\right) p_{2} \frac{S_{2}}{r_{2}}\right] \\
\left.=-\frac{\mu_{0}}{2 \pi} \frac{d I}{d t} \operatorname{sign}\left(\overrightarrow{M C} \cdot \overrightarrow{u_{\perp}}\right) p o l_{\perp}\left[\begin{array}{l}
\perp \\
r_{1}
\end{array}\right] \frac{1}{r_{2}}\right]
\end{gathered}
$$

With pol $_{1}=-$ pol $_{2}=+$ pol and $S_{1}=S_{2}=S$, and that the no verl ne does not cross the loop (i.e., $C$, $C_{1}$ et $C_{2}$ are on the same side of the powerline).

$$
\begin{gathered}
r_{1}=d-\frac{L}{\sqrt{2}} \sin \varphi \text { and } r_{2}=d+\frac{L}{\sqrt{2}} \sin \varphi \\
\frac{1}{r_{1}}-\frac{1}{r_{2}}=\frac{r_{2}-r_{1}}{r_{1} r_{2}}=-\frac{\sqrt{2} L \sin \varphi}{d^{2}-\frac{L^{2}}{2} \sin ,} \approx \frac{\sqrt{ } L_{L}}{d^{2}} \sin \varphi \text { with }\left(\frac{L^{2}}{d^{2}} \ll 1\right) \\
\varepsilon=-\frac{\mu_{0}}{2 \pi} \frac{d I}{d t} \operatorname{sir} n\left(\bar{\Gamma} \bar{C} \cdot \overrightarrow{u_{\perp}}\right) \text { pol } S \frac{\sqrt{2} L}{d^{2}} \sin \varphi
\end{gathered}
$$

We find the same formula as previously : using he value of the $B_{z}$ gradient at the center of the figure8 loop and considering that it is constant a. the figure- 8 loop scale, or using the $B_{z}$ value at the center of each square loop and considering it $\mathrm{c}^{-}{ }^{+}$an ${ }^{\prime}$ at the scale of each loop gives the same result if we are far enough from the powerline $\left(L^{2} \ll d^{2}\right)$

\section{Credit author statement}

$$
\varepsilon \approx-\frac{d}{d}\left[-2 \frac{1}{\sim}-B_{Z}^{2}\right] S \text { pol } \approx-\vec{\nabla}\left(\frac{\partial B_{Z}}{\partial t}\right) \cdot \overrightarrow{C_{2} C_{1}} \text { Spol }
$$

Girard Jean-François: Cc`cep ualization, Methodology, Software, Field work, Writing

Jodry Clara : Methodols gy, Software, Field work, Writing

Matthey Pierre-Danı ' : Ha dware (electronics), Field work

\section{Declaration of interests}

$\bigotimes$ The authors declare that they have no known competing financial interests or personal relationships that could have appeared to influence the work reported in this paper.

$\bigotimes$ The authors declare the following financial interests/personal relationships which may be considered as potential competing interests:

none 


\section{Highlights :}

- A new approach is proposed to improve the use of figure-of-eight loops for measuring Magnetic Resonance Sounding

- A new methodology is proposed to perform quickly in-situ statistics of the best orientation for a figure-8 MRS loop and evaluate final performance.

- Efficiency of figure- 8 filtering and impact of the position of the pair of small figure- 8 loops are tested numerically for some scenarios in the vicinity of powerlines.

- The methodology applied on a field dataset allows finding a stable best direction in this case, and underlines a surprising roughly common behavior for the harmonics of the industrial current and for frequencies in-between where a less organized structure was expected. 

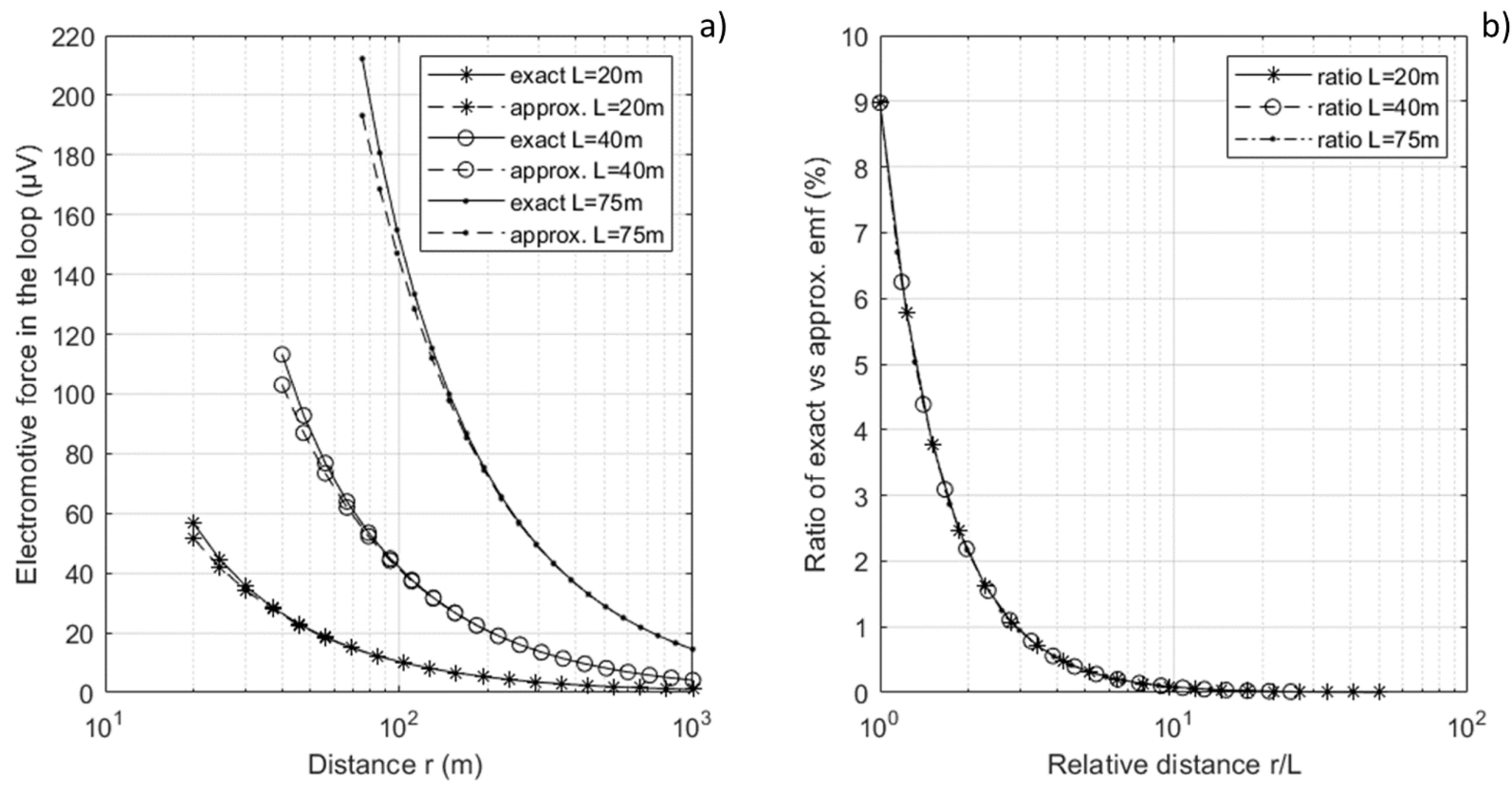

Figure 1 


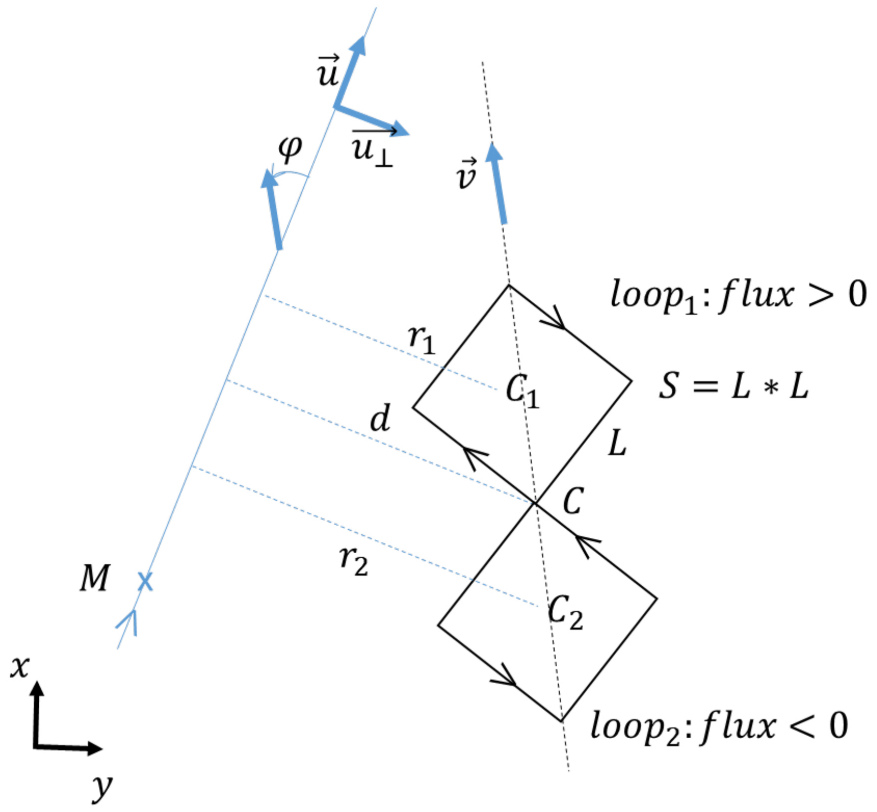

Figure 2 


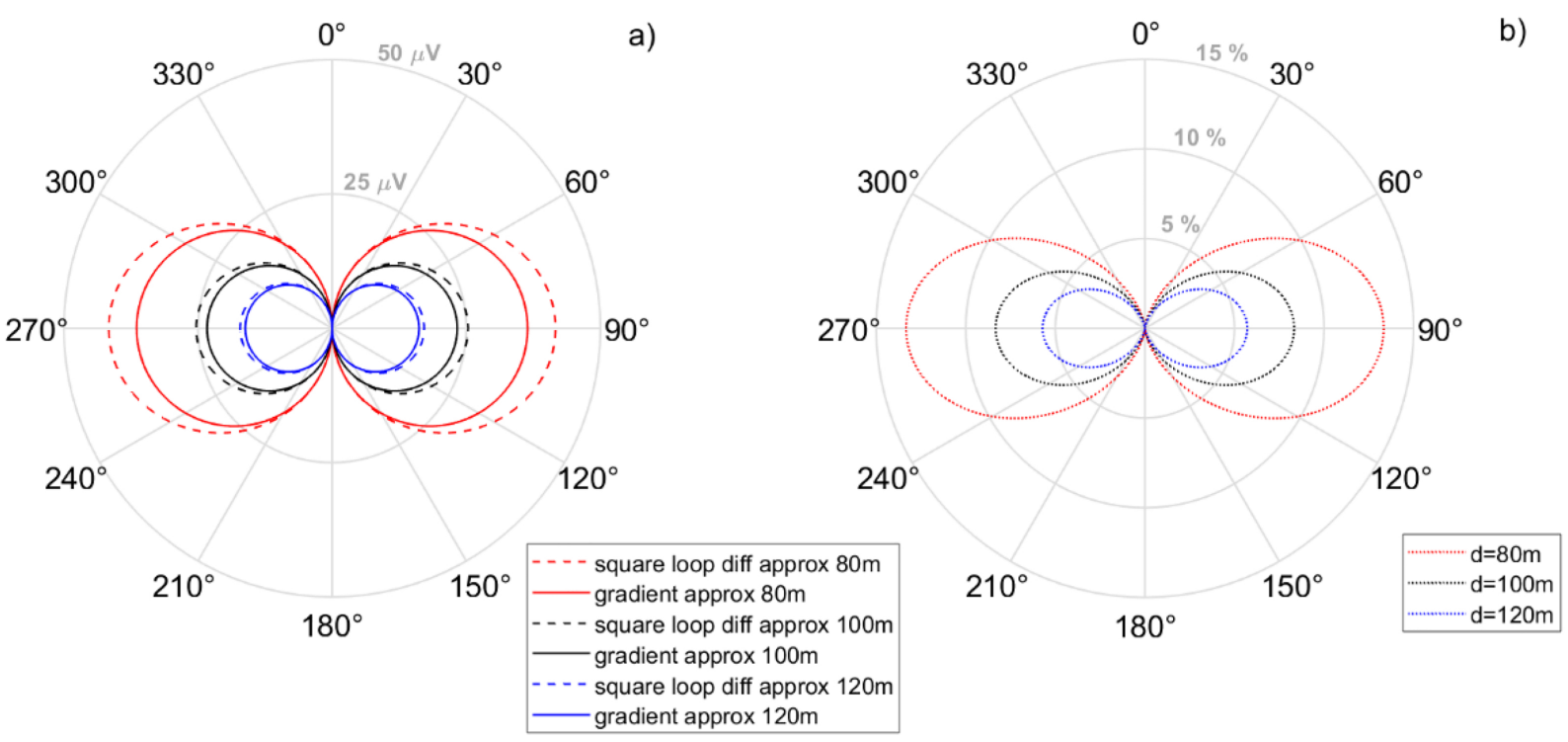

Figure 3 


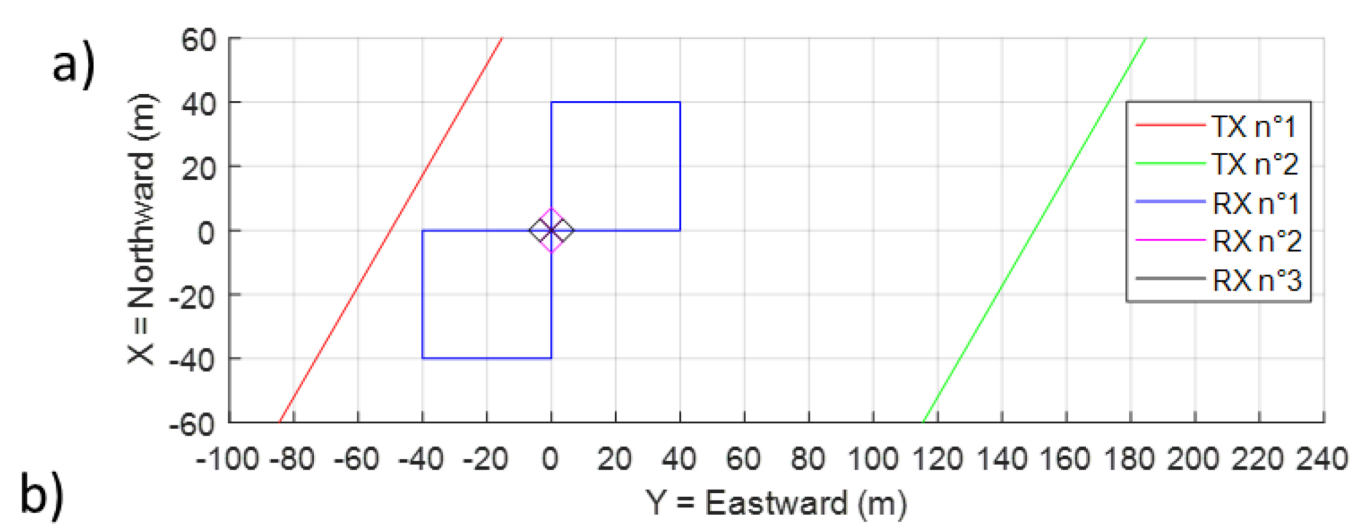

c)
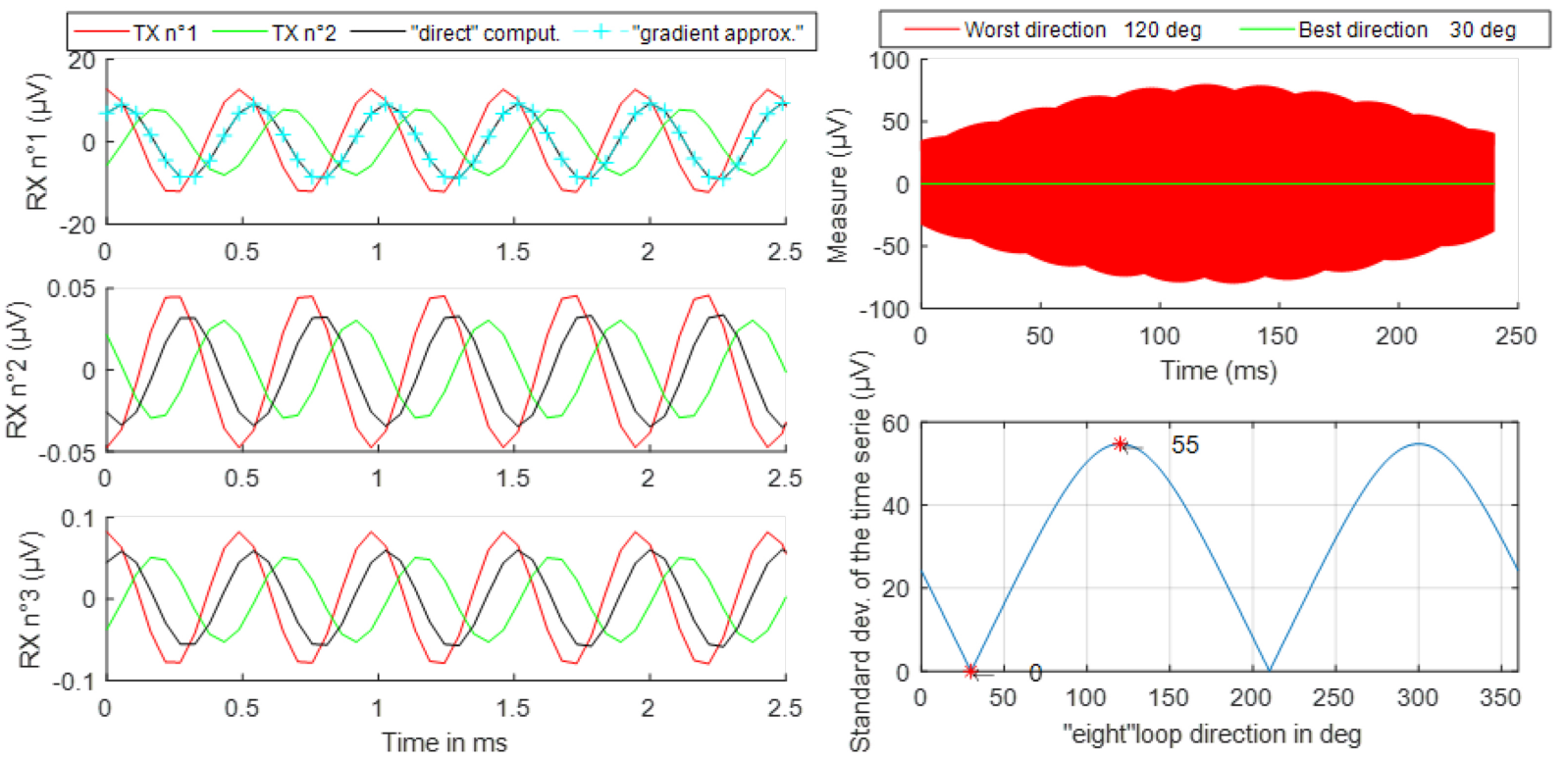

Figure 4 
a)

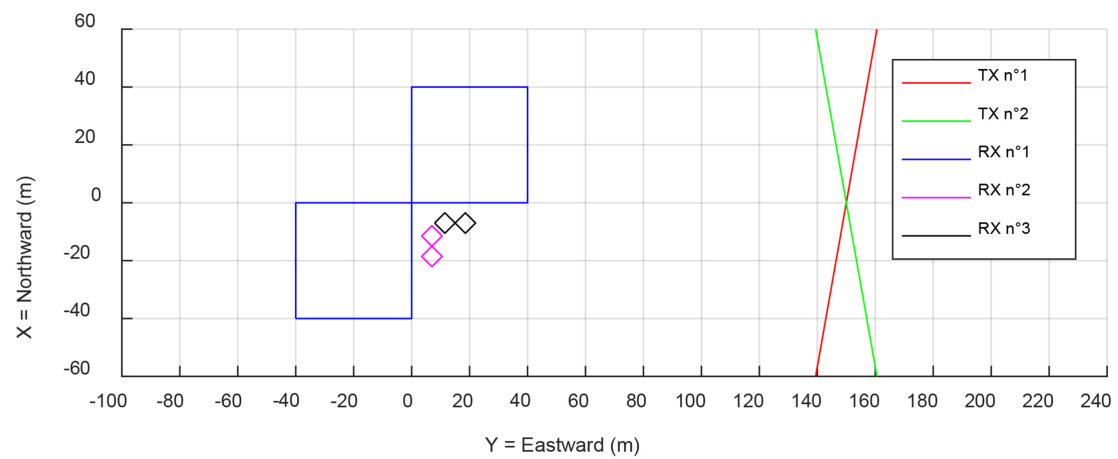

b)
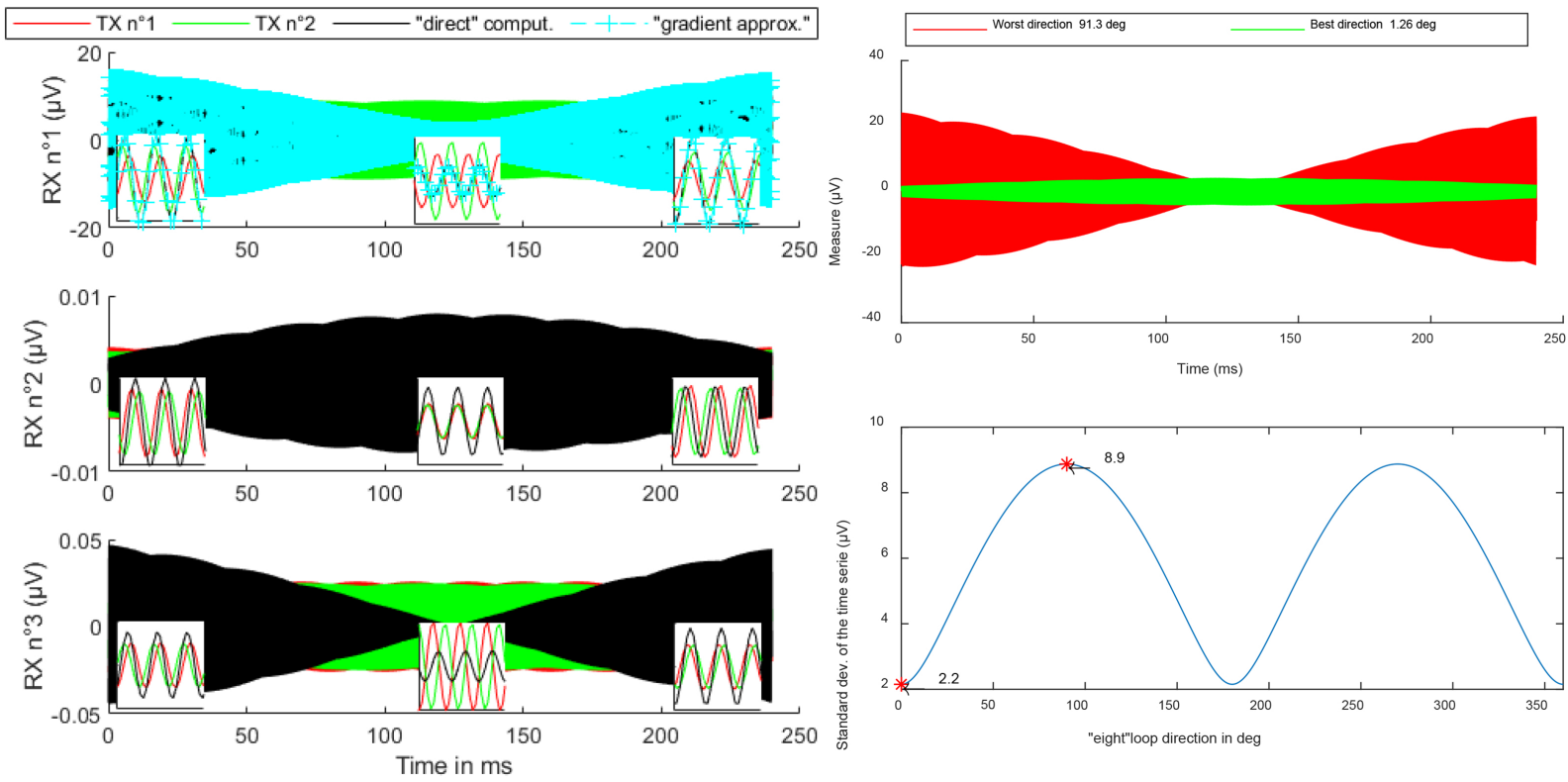

Figure 5 
a) Case 8

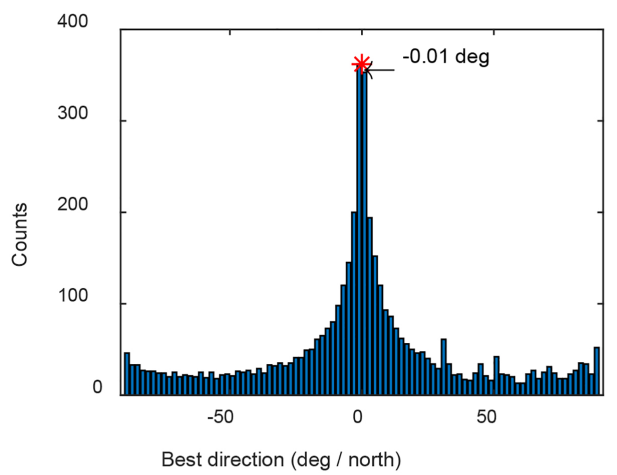

\section{b) Case 9}

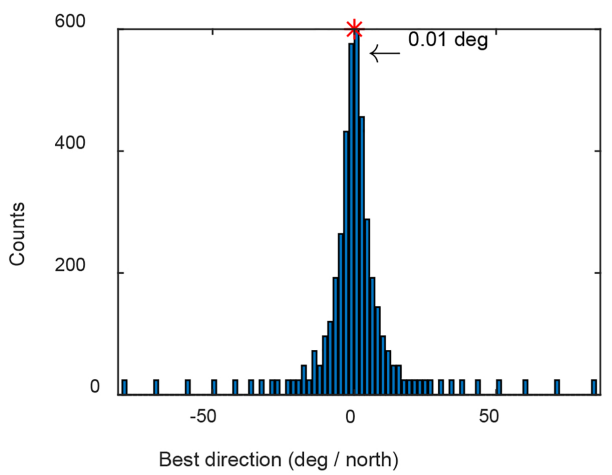

c) Case 10 centered

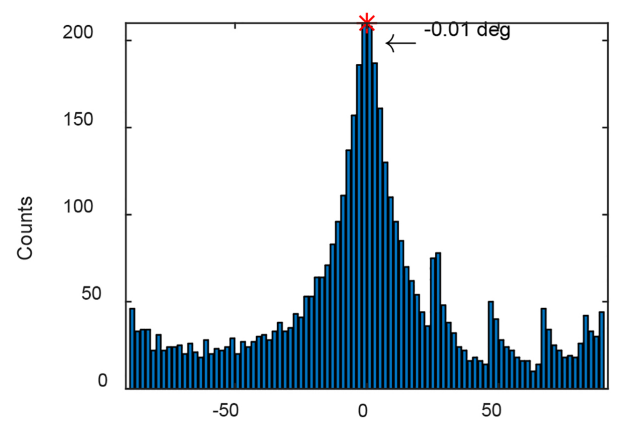

Best direction (deg / north) d) Case 10 (RX 2 \& 3 not centered on RX 1)

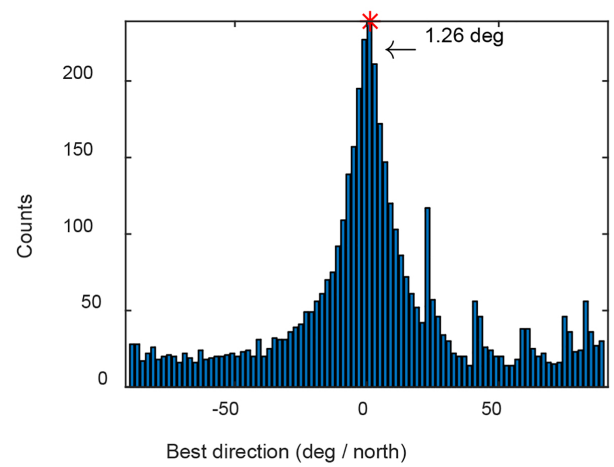

Figure 6 


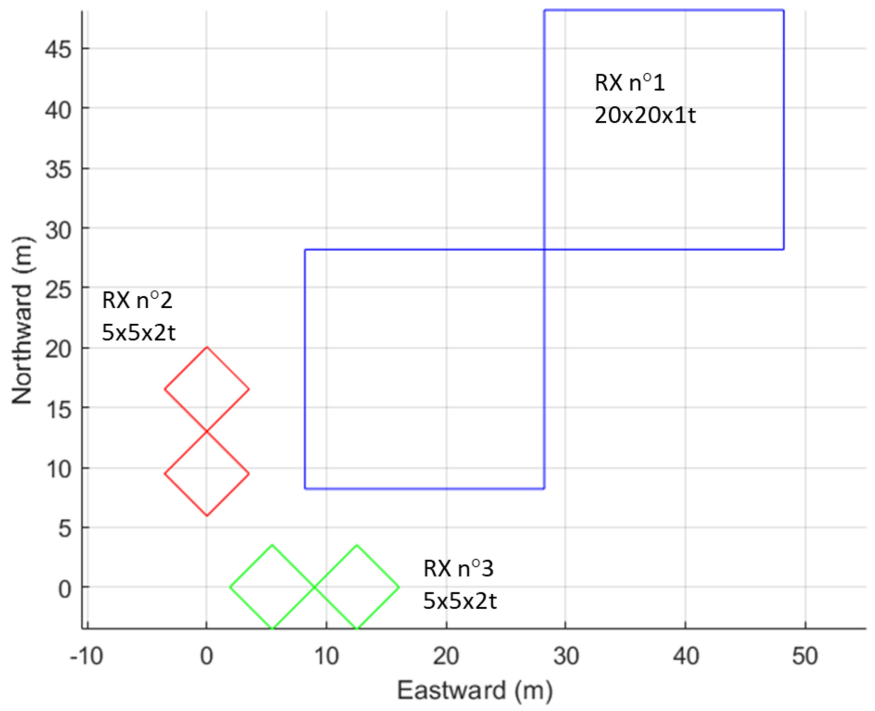

Figure 7 


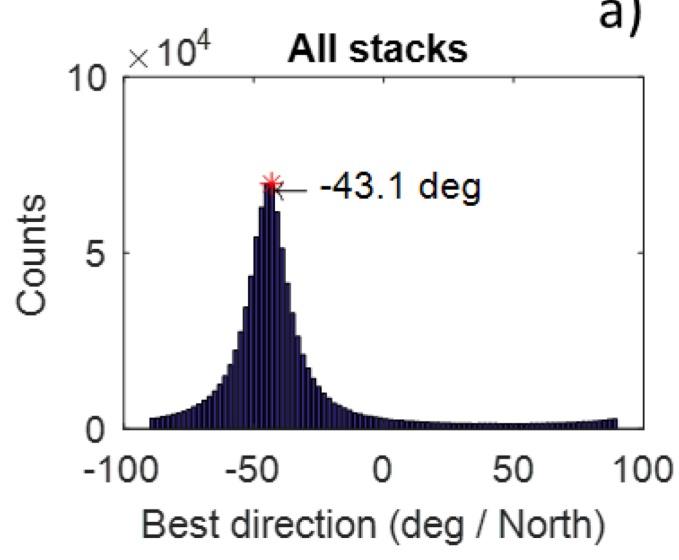

Time distribution, $240 \mathrm{~ms} \quad$ b)

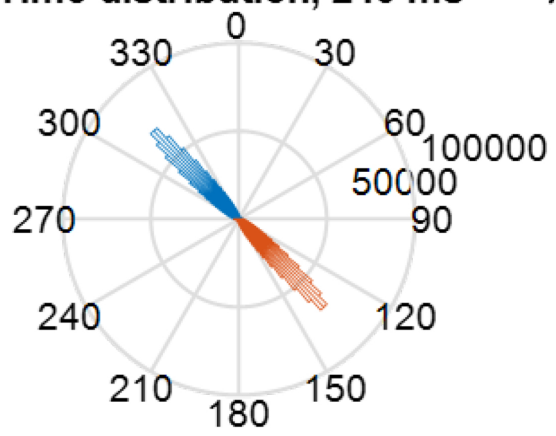

Figure 8 
Time serie of stack $n^{\circ} 101$

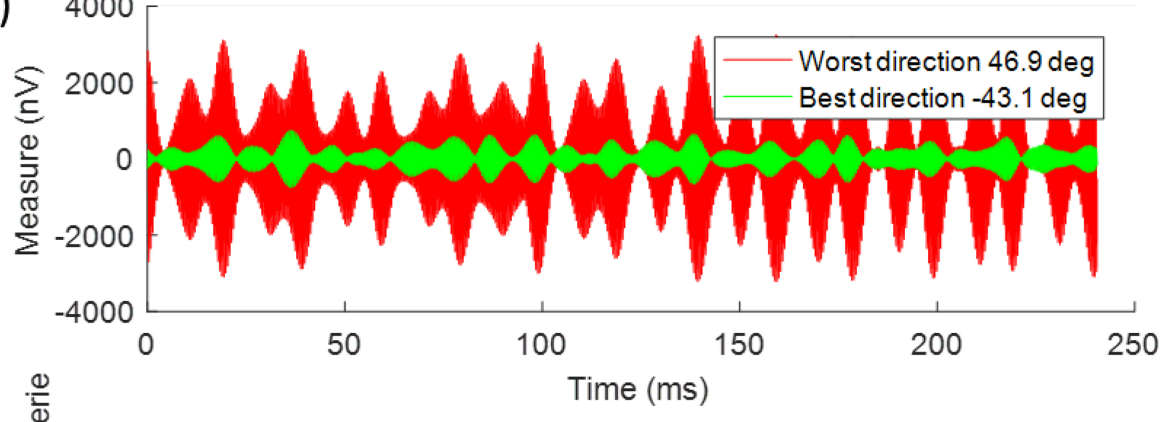

b)

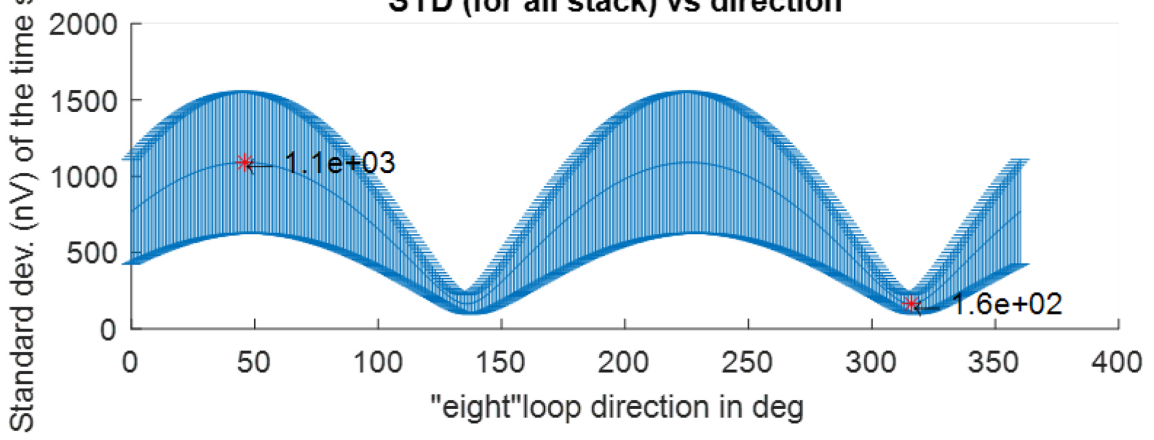

Figure 9 


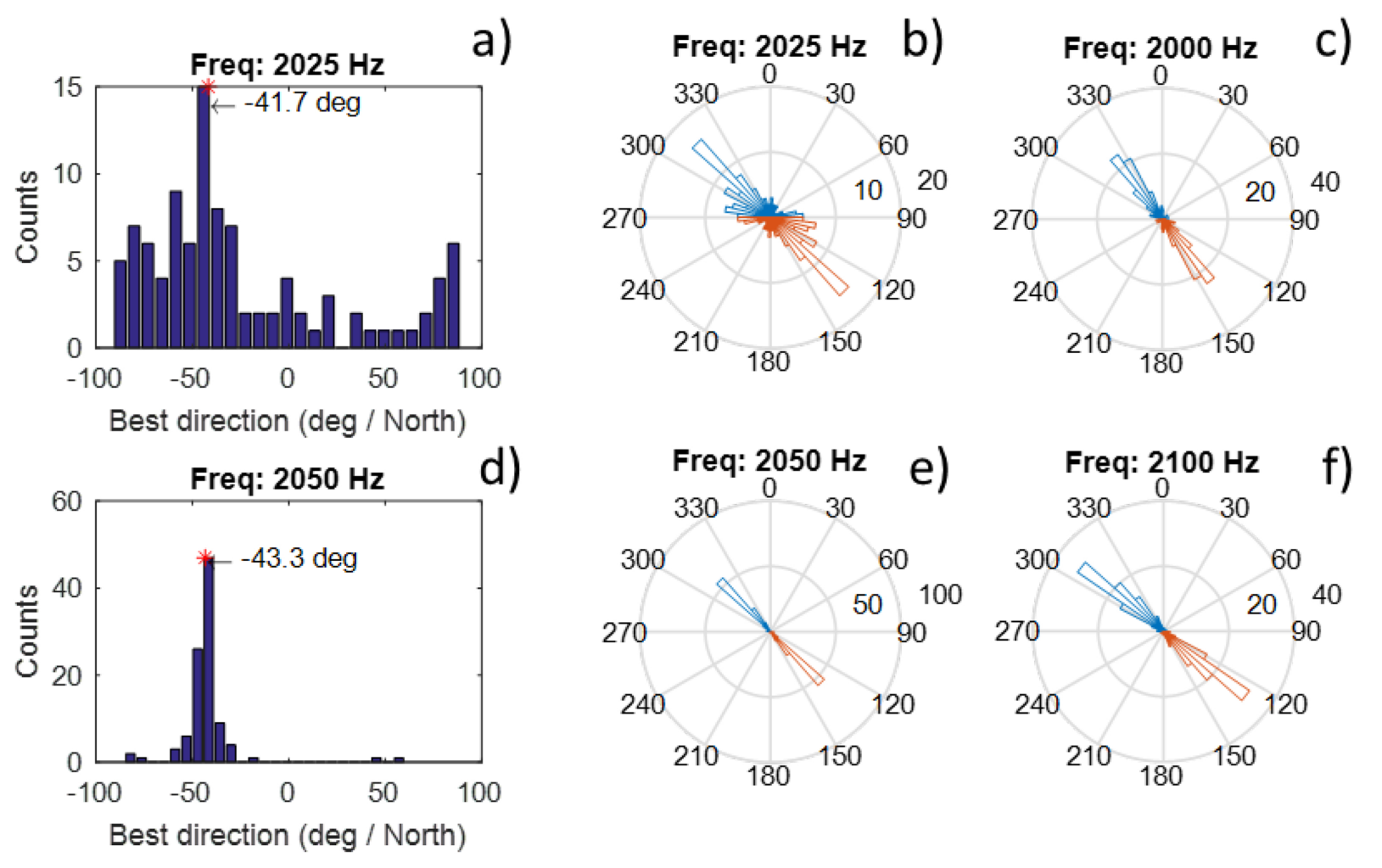



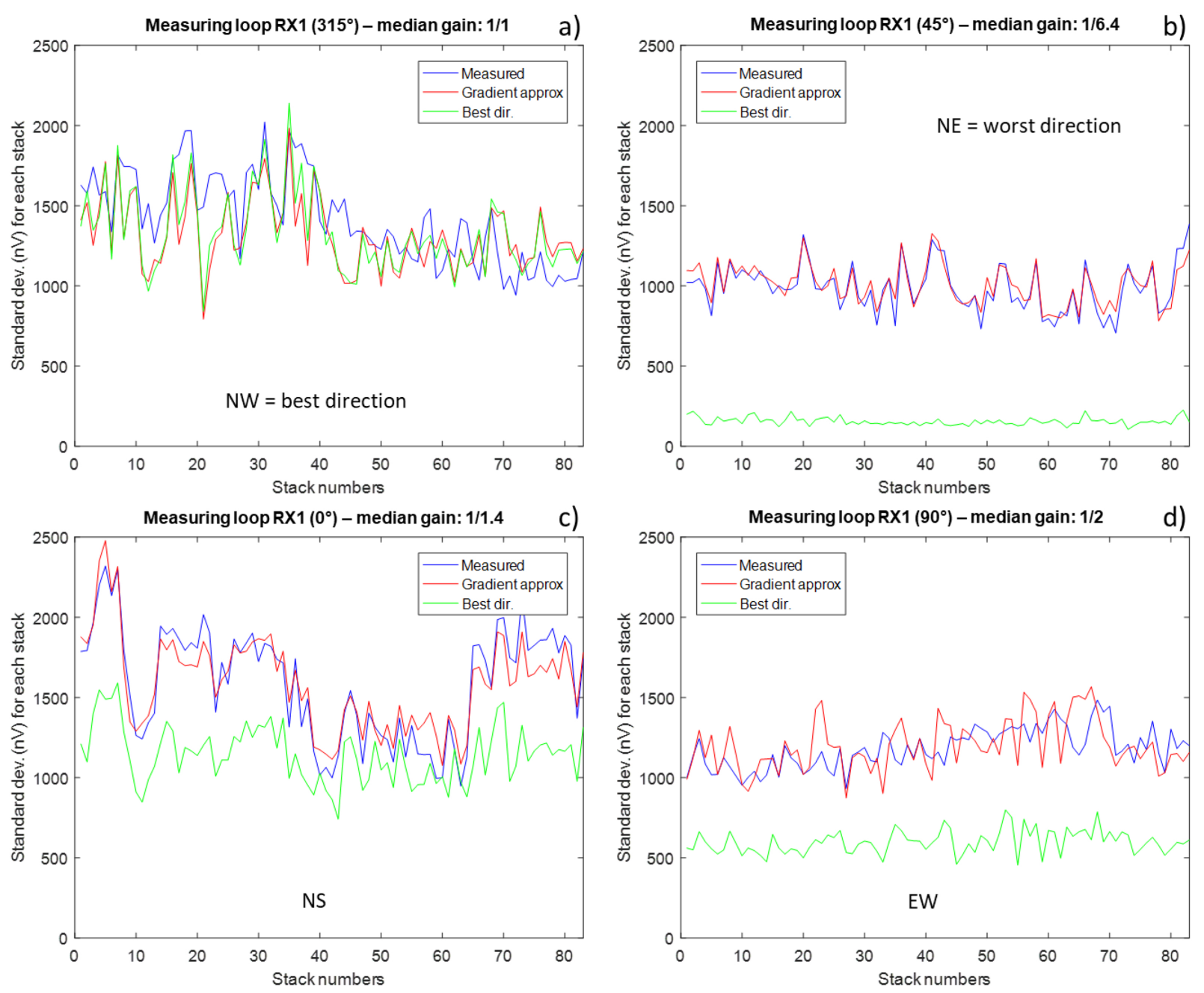

Figure 11 


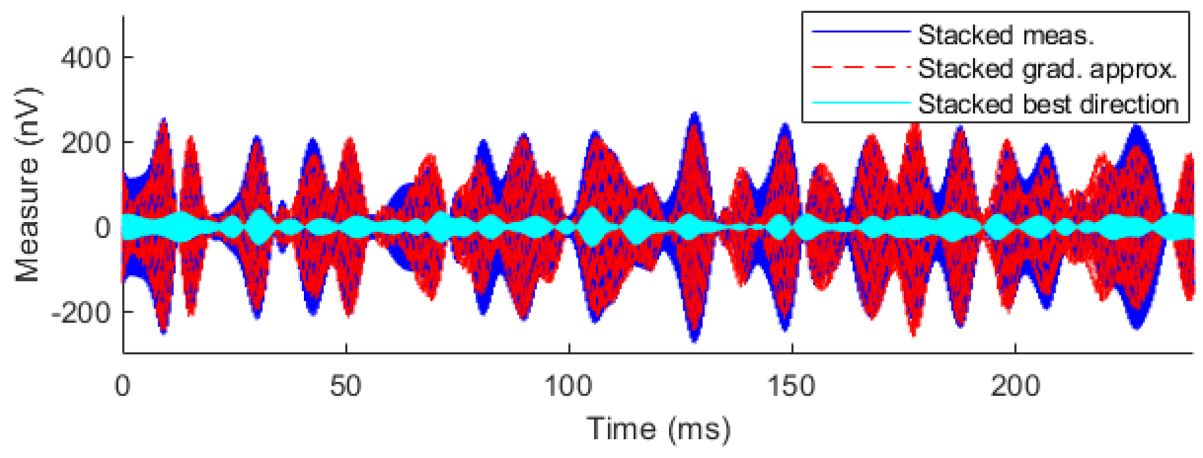

Figure 12 